\title{
Behaviour of a biocompatible titanium alloy during orthogonal micro-cutting employing green machining techniques
}

Carlos Henrique Lauro; Lincoln Cardoso Brandão; Sérgio Luiz Moni Ribeiro Filho; João Paulo Davim

\footnotetext{
${ }^{1}$ Dept. of Mechanical Engineering, University of Aveiro, Campus Santiago, 3810-193 Aveiro, Portugal. carlos.lauro@ua.pt

${ }^{2}$ Department of Mechanical Engineering, Centre for Innovation in Sustainable Manufacturing, Federal University of São João del Rei, Praça Frei Orlando 170, 36307-352 São João del Rei, Brazil. lincoln@ufsj.edu.br

${ }^{3}$ Department of Mechanical Engineering, Centre for Innovation in Sustainable Manufacturing, Federal University of São João del Rei, Praça Frei Orlando 170, 36307-352 São João del Rei, Brazil. sergiolmrf@gmail.com

${ }^{4}$ Dept. of Mechanical Engineering, University of Aveiro, Campus Santiago, 3810-193 Aveiro, Portugal. pdavim@ua.pt
}

\begin{abstract}
The sustainability of a process is the objective of modern industries aiming to reduce waste in production, since consumers require high quality and efficiency with fair price. Thus, a good understanding of the process should be its starting point. The manufacture of dental implants is an example in which waste reduction is important for the reduction of prices due to the demand for great quality and accuracy. This study observed the behaviour of sustainable micro-cutting applied to the Ti-6Al-7Nb titanium alloy, considering the ploughing effect on minimum quantity lubrication (MQL) and high-speed machining (HSM) conditions. When compared with dry condition and low-speed cutting in orthogonal micro-cutting, the use of HSM in dry cutting was more efficient than using MQL. The dry condition presented lower surface roughness, whilst the cooled/lubricated condition presented lower burr formation.
\end{abstract}

Keywords: Sustainable machining; Biomaterial; Titanium alloy; Surface quality; MQL system; Micro-cutting

Nomenclature

$b_{c} \quad$ Chip width

$f \quad$ Feed rate $(\mathrm{m} / \mathrm{min})$

$F_{c} \quad$ Cutting force $(N)$

$F_{R} \quad$ Machining force (N)

$F_{T} \quad$ Thrust force $(N)$

$h \quad$ Uncut chip thickness

$h_{c} \quad$ Chip thickness

$H R_{c}$ Hardness rockwell scale C

HSM High-speed machining
MQL Minimum quantity lubrication

$n \quad$ Spindle speed

$R_{a} \quad$ Arithmetic average roughness ( $\left.\mu \mathrm{m}\right)$

$r_{e} \quad$ Cutting edge radius

$R_{t} \quad$ Maximum roughness height $(\mu m)$

$R_{z} \quad$ Mean roughness depth $(\mu \mathrm{m})$

$u_{c} \quad$ Specific cutting energy $\left(\mathrm{J} / \mathrm{mm}^{3}\right)$

$\mu \quad$ Friction coefficient 


\section{Introduction}

Many investigations on micro-machining processes have been developed in the last decades. In the literature, many studies about micro-machining can be found [1, 2]; however, the subject of micro-machining processes still has many gaps to be filled. Micro-cutting processes present several advantages, such as the good surface integrity [3]. In the micro-milling of the Al 2011 aluminium alloy, Cardoso and Davim [4] obtained a maximum value of Ra surface roughness of $0.115 \mu \mathrm{m}$. Bodziak et al. [5] observed that the electro-discharge machining (EDM) process can be replaced by the micro-milling process with similar metal removal rates, elimination of complementary proceedings and higher quality.

Micro-cutting processes have a serious disadvantage, the size effect. Depending on the cutting edge radius $\left(r_{e}\right)$, feed rate $(f)$ and spindle speed (n), cutting can occur without chip formation due to the ploughing effect, resulting in a machined surface of poor quality [6]. The influence of the cutting parameters differs in the micro-machining domains and is also in contrast to conventional machining [7]. According to Chae et al. [8], the concept of minimum chip thickness is that the depth of cut or feed must be over a certain critical chip thickness before a chip will form. Thus, if the uncut chip thickness (h) is less than a critical minimum chip thickness, hm, elastic deformation occurs and the cutter does not remove any workpiece material. Oliveira et al. [9] observed that due to the size effect, the specific cutting force is strongly affected by the feed rate on the micro-scale. The author observed that the specific cutting force was greater for micro-milling than for macromilling, in around $90 \%$.

$\mathrm{Ng}$ et al. [10] observed a growth of the specific cutting energy and coefficient of friction when the undeformed chip thickness/cutting edge radius ratio was reduced. In micro-machining, the chip formation is an interesting aspect. Generally, the uncut chip thickness is smaller than the cutting edge radius and the chip forms in the area of the edge radius [11]. The micro-machining can be considered when the undeformed chip thickness below the tool edge radius and above the tool edge radius [7].

In the micro-turning of the Ti-6Al-4V titanium alloy, Jagadesh and Samuel [12] observed that the increase of cutting speed caused a reduction in cutting forces when the uncut chip thickness was higher than the cutting edge radius because the temperature in the tool chip interface increased. In the analysis of the micro-cutting of the Ti-6Al-4V titanium alloy with an uncut chip thickness of 1 $\mu \mathrm{m}$, Ducobu et al. [13] observed that the thrust force is larger than the cutting force, which goes against the conventional cutting theory.

Currently, as well as any manufacturing process, machining processes should be sustainable. In other words, the process should result in minimum waste and environmental impact. According 
to Bhanot et al. [14], nowadays, sustainable manufacturing should be discussed in the manufacturing industry, because it approaches essential competitive manufacturing issues (cost, quality, environmental impact, health, safety and others). The authors highlighted the complexity of manufacturing processes, wherein a change of one parameter can increase the cutting quality, although it can also increase production cost.

In conventional machining, several techniques have been studied with the objective of reducing the environmental or/ and financial impacts resulting from production. The use of cutting fluids can improve machined surface quality, tool life and cutting forces due to the reduction of chip/tool friction. However, conventional cooling/lubrication employs miscible water and mineral oil, materials that are difficult to prepare and dispose; furthermore, bacteria and fungi can easily grow in these fluids [15]. Thus, several alternatives for these issues, of environmental and biological character, have been studied for industrial and academic purposes in the last years. Amongst these solutions, the minimum quantity lubrication (MQL) system has been employed because it maintains the reduction of friction, temperature and others, functioning in harmony with wet machining with its lower consumption of cutting fluids and absence of damage to the machined surface and/or the production. Furthermore, for the MQL system, flow rates can be reduced up to 10,000times when compared to wet machining [16].

Pusavec et al. [17] highlighted that sustainable processes are replacing oil-based flood cooling emulsions and improving dimensional accuracy, surface integrity, material removal rate, chip breakability and others. Regarding the grinding process, Rabieia et al. [18] cited that an advantage of the use of the MQL system is the precise delivery of oil mist to the workpiece-grain interface. It can cause a reduction of tangential forces when compared to fluid cooling because the effective lubrication creates a durable lubricant tribofilm. Al Ghamdi and Iqbal [19] affirmed that important sustainability measures are the materials’ yield strength and cutting speed. The author observed that high-speed machining (HSM) is a sustainable procedure, which can improve productivity and reduce specific energy consumption.

Sustainable machining techniques, such as the MQL system and HSM, have been studied with the objective of improving surface quality in micro-machining processes. Li and Chou [20] analysed the effects of the MQL system on the micro-milling of the AISI H13 steel with 32 HRC. The authors observed that the use of the MQL system can minimise burr formation due to low wear of the tool, also presenting lower values of Ra surface roughness, which experienced an abrupt increase in dry condition. Burr control in biomedical components is important because they require that burr height should be lower than $25 \mathrm{~nm}$ [21]. In the micro-milling of the Ti-6Al-4V titanium alloy, Baldo et al. [22] obtained lower surface roughness when employing new tools, with high machining speed. 
The present work analysed the behaviour of the ploughing effect on the orthogonal microcutting of the Ti-6Al-7Nb titanium alloy whilst employing the MQL system and the HSM. The aim was to verify if the cooling/lubricating or the HSM could reduce the ploughing effect, which negatively influences the micro-machined surface. To this end, the cutting forces, the friction coefficient, the specific cutting energy, the shear plane, the chip and the quality of the micromachined surface were compared.

\section{State of the art}

\subsection{Orthogonal cutting}

Orthogonal cutting, according to Fig. 1, is a type of cutting mechanism that has been applied in many machining process studies. Because of its simplicity, it can help to understand the basic mechanics of the machining process. Several researchers develop their models based on orthogonal cutting model [23]. Orthogonal cutting is a simplified cutting operation, it is only in two dimensions, that is used in the first stages of investigations [24]. Thus, the existence of only two cutting force components, or the fact that uncut chip thickness (h) can be considered equal to feed rate, are aspects that simplify orthogonal cutting model.

Orthogonal cutting was utilised for the study of several machining phenomena in the AISI 1045 steel [25], Ti-6Al7Nb titanium alloy [26] or bone [27]. To compare the macro-scale with orthogonal cutting, Fromentin et al. [28] developed a laboratory machine to study micro-cutting. The authors performed some micro-cutting tests to observe models of micro-cutting, such as the influence of lubrication in the cutting forces, chipping and the nominal value of cutting depth in the micro-cutting of 316-L stainless steel with a tungsten carbide (WC) insert. Liu and Melkote [29] developed a FEM model to study the influence of tool edge radius on size effect in the orthogonal micro-cutting process, observing a nonlinear growth of the specific cutting energy when the uncut chip thickness approximated the edge radius.

Schneider et al. [30] used orthogonal micro-cutting to study the influence of the rake angle in micro-cutting of commercially pure titanium. They observed that an increase of the rake angle can improve the quality of the surface due to its reducing of the plastic deformation in chip formation, regardless of the uncut chip thickness.

\subsection{Biomaterial}

Biomaterial can be described as any substance or combination of substances, synthetic or natural in origin, capable of augmenting or replacing any tissue, organ or function of the body, prolonging or improving the quality of life of an individual [31]. The necessity for hard tissue 
reconstruction was responsible for the development of several titanium alloys that, together with pure titanium, are the metallic materials of preference for use in biomedical applications [32]. The great feature that Ti-6Al-4V (112 GPa), Ti-6Al-7Nb (110 GPa) and other titanium alloys has is a low elastic modulus, close to the elastic modulus of the bone (30 GPa), in comparison with Co-Cr alloys (240 GPa) and AISI 316-L stainless steel (210 GPa) [33]. Amongst the titanium alloys, the Ti-6Al-4V titanium alloy is the most employed in biomedical applications [34]. However, the use of materials that remove vanadium (V-free) from titanium alloys for medical application has been debated since the mid-1980s in the USA [35]. It is because the potential toxicity of vanadium can cause cytotoxicity and adverse body tissue reactions [36].

Thus, new titanium alloys have been developed to replace the vanadium, such as the Ti-Mn [37], Ti-6Al-7Nb, Ti-5Al2.5Fe, Ti-13Nb-13Zr and Ti-35Nb-5Ta-7Zr titanium alloys [36]. Nevertheless, the number of studies related to these new alloys are still lower than those developed for the Ti6Al-4V titanium alloy or for pure titanium. A brief search on the Engineering Village database showed that, when compared to articles on the Ti-6Al-4V titanium alloy and pure titanium between 1999 and 2018, the number of papers about the Ti-6Al-7Nb and Ti-5Al-2.5Fe alloys represented about $2.2 \%$ of the total (Fig. 2).

In their study on titanium foams, Bütev et al. [39] mentioned that the mechanical properties and bioactivities are not clearly defined for the Ti-6Al-7Nb titanium alloy. The titanium foams can reduce mechanical mismatch, which occurs due to differences in the elastic modulus between bone and implant. Schueler et al. [40] analysed micro-milling on the Ti-6Al-7Nb and Ti-6Al-4V titanium alloys, observing how the $\mathrm{R}_{\mathrm{a}}$ surface roughness values of both grew closer when using the highestlevel feed rate.

\section{Materials and methods}

The titanium alloy was used in this work because this material is widely employed in medical/dental implants. Dental implants can be considered components in meso/micro-scale that require high surface quality. ATi-6Al-7Nb titanium alloy bar with a diameter of $13 \mathrm{~mm}$ and a hardness of $32 \mathrm{HR}_{\mathrm{C}}$ from

TiFast S.r.l. was used. The material presented a chemical composition of aluminium (5.946.02\%), carbon (0.013\%), iron (0.15-0.16\%), hydrogen $(0.003 \%)$, nitrogen $(0.005 \%)$, niobium (6.83-6.90\%), oxygen (0.169-0.178\%), tantalum $(0.05 \%)$ and titanium (in balance). The workpieces were machined in wet condition to obtain a tube with a wall thickness of $1.1 \mathrm{~mm}$.

The tests were performed with uncoated carbide flat inserts (TPGN $160304 \mathrm{H} 13 \mathrm{~A}$ ) that were mounted in a tool holder (CTGPL 2020K16) with a rake angle $(\gamma)$ of $6^{\circ}$, a tool cutting edge angle of $91^{\circ}$ and a cutting edge inclination angle of $0^{\circ}$. The inserts and tool holder were provided by Sandvik 
Coromant $^{\mathrm{TM}}$. The cutting edge radius $\left(\mathrm{r}_{\mathrm{e}}\right.$ ) of the inserts has about of $20 \mu \mathrm{m}$. To avoid the influence of the corner radius $(0.4 \mathrm{~mm})$, the penetration of the tool was of $1.6 \mathrm{~mm}$.

In this analysis, in order to understand the influence of cooling/lubrication on orthogonal micro-cutting, three two level factors were analysed (cutting speed, feed rate and cooling condition). Cutting speed ( $\left.v_{c}\right)$ was fixed at $30 \mathrm{~m} / \mathrm{min}$ (low speed) and $120 \mathrm{~m} / \mathrm{min}$ (high speed). Feed rate $(f)$ was defined at $10 \mu \mathrm{m} / \mathrm{rev}\left(f / r_{e}<1\right)$ and $50 \mu \mathrm{m} / \mathrm{rev}\left(f / r_{e}>1\right)$. Dry and cooling/lubrication cutting methods were employed to analyse the influence of cooling/lubrication on the ploughing effect. The MQL system was composed by Unist ${ }^{\mathrm{TM}}$ MQL, Coolubricator JR model, with Coolube ${ }^{\mathrm{TM}}$ 2210 biodegradable oil. Flow rate was fixed at $2.6 \mathrm{ml} / \mathrm{min}$ and pressure of 6 bar. Table 1 shows the factors and levels used in this work.

Table 1 - Experimental planning in the micro-cutting tests

\begin{tabular}{ccc}
\hline Factor & Level \\
& Low & High \\
\hline Cutting speed $\left(v_{c}\right)(\mathrm{m} / \mathrm{min})$ & 30 & 120 \\
Feed rate $(f)(\mu \mathrm{m} / \mathrm{rev})$ & 10 & 50 \\
Cooling/lubrication condition & Dry & $\mathrm{MQL}$ \\
\hline
\end{tabular}

The cutting forces were reached using a Kistler ${ }^{\mathrm{TM}}$ piezoelectric dynamometer model 9121, a Kistler $^{\mathrm{TM}}$ charge amplifier model 5019B. Figure 3 shows the experimental setup for the microcutting tests. To measure surface roughness, a Taylor Hobson ${ }^{\mathrm{TM}}$ profilometer, Talyrond 131c model, was used. The surface was characterised through the Ra, Rz and Rt profiles using four sampling lengths (cut off of $0.8 \mathrm{~mm}$ ). In each test, three surface roughness measures with $120^{\circ}$ angular separation were taken in order to reduce experimental errors (see Fig. 4). The micro-machined surfaces and chips were observed using a Hitachi ${ }^{\mathrm{TM}}$ scanning electron microscope (SEM), SU-70 model. 3.1 Treatment of cutting forces and chip

The methodology to acquire and process the force signals during the orthogonal micro-cutting process, and to calculate the response, was based on Lauro et al. [41]. The cutting force signal was acquired using a sampling rate of $4 \mathrm{kHz}$, acquisition time of $300 \mathrm{~s}$, manually triggered. In order to denoise the acquired signal, a wavelet transform was applied. The values of the cutting forces were defined by the average of peak (maximum values) acquired during cutting, discarding a small section in the beginning and end of the cut due to inertia. To find the machining force (FR), Eq. (1) was used, which corresponded to an average of the acquired points. The friction coefficient $(\mu)$ and specific cutting energy $\left(u_{c}\right)$ were calculated using Eqs. (2) and (3), respectively. Their responses were calculated for each acquired point, and the average of these points was used for comparison. 


$$
F_{R}=\frac{\sum_{1}^{n} \sqrt{F_{T_{i}{ }^{2}}+F_{c_{i}{ }^{2}}}}{n}
$$

Where, $F_{T}$ is the thrust force $(\mathrm{N}) ; F_{c}$ is the cutting force $(\mathrm{N}) ; i$ is the time increment; and $n$ is the number of increments.

$$
\mu=\frac{\sum_{1}^{n} \frac{F_{T_{i}}+F_{c_{i}} i \tan \gamma}{F_{c_{i}}-F_{T_{i}} i \tan \gamma}}{n}
$$

Where, $\gamma$ is the tool rake angle.

$$
u_{c}=\frac{\sum_{1}^{n} \frac{v_{c}}{V_{\mathrm{rem}}} \cdot i \sqrt{F_{T_{i}}+F_{C_{i}}} i \Delta \mathrm{t}}{i^{n}}
$$

where $u_{c}$ is the specific cutting energy $(\mathrm{J} / \mathrm{mm} 3)$, FT is the thrust force $(\mathrm{N})$, Fc is the cutting force $(\mathrm{N}), v_{c}$ is the cutting speed $(\mathrm{m} / \mathrm{s}), V_{\text {rem }}$ is the removed chip volume (mm3) and $\Delta \mathrm{t}$ is the equally spaced time interval (s).

To define chip thickness (h), we calculated the average of ten measures that were used for finding the chip compression ratio (ל; see Eq. (4)). Before carrying out the measurement of the chips' dimensions, they were cleaned and dried to avoid uncertainty due to the presence of oil. To analyse the shear plane angle $(\varphi)$, the Lee-Shaffer model (Eq. (5)) was used. In this model, we observed a great response in order to identify the ploughing effect, when the angle is lower than $10^{\circ}$ [41].

$$
\zeta=\frac{t_{c}}{t}
$$

Where, $t_{c}$ is the chip thickness (mm); $\mathrm{t}$ is the uncut chip thickness (mm).

$$
\varphi_{\text {Lee - Shaffer }}=\frac{\pi}{4}-\arctan \mu+\gamma
$$

where $\gamma$ is the tool rake angle, $\mu$ is the friction coefficient (Eq. (1)) and $\zeta$ is the chip compression ratio (Eq. (3)).

\section{Results and discussion}

\subsection{Cutting forces}


Figure 5 shows the values of the $F_{T}$ (thrust) force in the orthogonal micro-cutting process in dry and cooled/lubricated conditions for different cutting parameters. The increase of the feed rate provided a significant variation in $F_{T}$ force values in both conditions, $66.3 \%$ for dry and $82.8 \%$ for MQL. The increase of the cutting speed caused a reduction in the $F_{T}$ force in all conditions, practically $10.9 \%$ on average. The use of the MQL system varied the $F_{T}$ force between -18.9 and $3.3 \%$ for the cutting speeds set at 30 and $120 \mathrm{~m} / \mathrm{min}$, respectively. Figure 6 shows the Pareto chart for the $F_{T}$ force. The use of cooling/lubrication reduced the magnitude effect for all parameters, and the "feed rate" remained important for the $F_{T}$ force.

The $F_{C}$ (cutting) force for the micro-cutting process is shown in Fig. 7. The increase of the feed rate caused a growth of $65.4 \%$ (dry) and $82.6 \%$ (MQL) in the $F_{C}$ force measurements, in average. The increase of the cutting speed reduced the $F_{C}$ force in all conditions practically, in an average of $10.9 \%$. The use of the MQL system decreased it, at a $v_{c}$ of $30 \mathrm{~m} / \mathrm{min}$, or increased, at a $v_{c}$ of $120 \mathrm{~m} / \mathrm{min}$. The Pareto chart for the $F_{C}$ force is shown in Fig. 8. The employment of the MQL system reduced the magnitude of the feed rate, and "cooling” became of no impact on the $F_{C}$ force.

Figure 9 shows the values of the $F_{R}$ (machining) force calculated in dry and cooled/lubricated micro-cutting. The increase of feed rate raised the $F_{R}$ force in $160.4 \%$ (dry) and $194.0 \%$ (MQL), on average. The increase of cutting speed reduced the $F_{R}$ force in $13.0 \%$ (dry) and 2.0\% (MQL). During the usage of the MQL system, the biggest reduction when employing it was in the condition with lower level ( $v_{c}=30 \mathrm{~m} / \mathrm{min}$ and $\left.f=10 \mu \mathrm{m}\right), 22.3 \%$. For the cutting speed of $120 \mathrm{~m} / \mathrm{min}$ and feed rate of $10 \mu \mathrm{m}$, the reduction was in $3.7 \%$. In the meantime, when comparing the dry cutting ( $v_{c}$ $=120 \mathrm{~m} / \mathrm{min}$ and $f=10 \mu \mathrm{m})$ and cooled/lubricated conditions $\left(\nu_{c}=30 \mathrm{~m} / \mathrm{min}\right.$ and $\left.f=10 \mu \mathrm{m}\right)$, the values of FR force were lower, in an average of $6.1 \%$. The reduction of the $F_{R}$ forces for the feed rate were $3.4 \%(30 \mathrm{~m} / \mathrm{min})$ and $1.2 \%(120 \mathrm{~m} / \mathrm{min})$, on average. Figure 10 shows the Pareto chart for the $F_{R}$ force. The "cutting speed" was of no impact and the magnitude of the feed rate was reduced for the $F_{R}$ force when using the MQL system.

\subsection{Specific cutting energy and friction coefficient}

The comparison of the specific cutting energy for dry and cooled/lubricated cutting is shown in Fig. 11. The cutting speed increased and the feed rate decreased; on average, the specific cutting energy increased in 13.0 and $47.9 \%$ for dry cutting and 2.0 and $41.2 \%$ for the MQL, respectively. When the MQL system was used, the reduction was higher in the low cutting speed (22.3 and 3.4\%) than the high cutting speed (3.7 and 1.2\%), in both feed rates (10 and $50 \mu \mathrm{m}$, respectively). The Pareto chart for the specific cutting energy is shown in Fig. 12. For the specific cutting energy, all parameters were important in the dry condition, but only the feed rate was important in the cooled/lubricated condition. 
Figure 13 shows the values of the friction coefficient between tool and chip in micro-cutting. The increase of the feed rate caused a reduction in the friction coefficient in the MQL (42.9\%) and dry (41.1\%) conditions. Except for the condition using MQL and low feed rate, the increase of cutting speed decreased the friction coefficient in all conditions, $8.2 \%$ on average. The employment of the MQL system varied the friction coefficient between $-8.2 \%\left(v_{c}=30 \mathrm{~m} / \mathrm{min}\right)$ and $5.6 \%\left(v_{c}=\right.$ $120 \mathrm{~m} / \mathrm{min}$ ). The Pareto chart for the friction coefficient is shown in Fig. 14. When the MQL system was employed, only the feed rate became important for the determination of the friction coefficient.

\subsection{Shear plane angle}

The values of the shear plane angle calculated by the Lee- Shaffer model is shown in Fig. 15. The increase of the feed rate sharply increased the shear plane angle in $221.4 \%$ (dry) and 254.3\% (MQL). The cutting speed variation, from 30 to $120 \mathrm{~m} / \mathrm{min}$, increased the shear plane angle for all conditions in at least $4.2 \%$, practically. The use of the MQL system caused an increase (20.8\% for $\left.v_{c}=30 \mathrm{~m} / \mathrm{min}\right)$ or a reduction $\left(14.8 \%\right.$ for $\left.v_{c}=30 \mathrm{~m} / \mathrm{min}\right)$. Figure 16 shows the Pareto chart for the shear plane angle. All parameters presented a reduction of the standardised effect magnitude; however, only feed rate was impacting on this response when using the MQL system.

\subsection{Chips}

The comparison between the dry and cooled/lubricated conditions for the chip compression ratio is shown in Fig. 17. The increase of the feed rate reduced the chip compression ratio in 33.5\% (dry) and 27.6\% (MQL). Similar evolution was observed for the cutting speed: a reduction of 18.8\% (dry) and 9.5\% (MQL), on average. The usage of cooled/lubrication in the micro-cutting process varied the values of the chip compression ratio in $-3.2 \%\left(v_{c}=30 \mathrm{~m} / \mathrm{min}\right)$ and $7.8 \%\left(v_{c}=120\right.$ $\mathrm{m} / \mathrm{min}$ ), on average. Figure 18 shows the Pareto chart for the chip compression ratio. When using the MQL system, the impact of the feed rate and cutting speed was reduced; however, this interaction presented the increase of the magnitude of chip compression ratio.

Figures 19 and 20 show the chip morphology of microcutting for the feed rates of 10 and 50 $\mu \mathrm{m} / \mathrm{rev}$, respectively. For the free surface of chip, the lamellar structures were more spaced during the increase of the feed rate and cutting speed. When analysing the effect of the cooled/lubricated condition, the spacing increased for the $v_{c}$ of $30 \mathrm{~m} / \mathrm{min}$ and decreased for the $v_{c}$ of $120 \mathrm{~m} / \mathrm{min}$.

\subsection{Surface roughness}

The values of the Ra, Rz and Rt surface roughness obtained in the micro-cutting process are shown in Fig. 21a, b, respectively. The surface roughness value for the feed rate of $50 \mu \mathrm{m} / \mathrm{rev}$ was lower than that of $10 \mu \mathrm{m} / \mathrm{rev}$ the feed rate: on average, 28.8\% (dry) and 34.3\% (MQL). It can be 
justified in light of the feed rate of $10 \mu \mathrm{m} / \mathrm{rev}$ suffering the ploughing effect, $\mathrm{f} / \mathrm{re}<1$, providing a surface with poor quality. The application of cooling/lubrication in the micro-cutting process increased the surface roughness values for all conditions, on average, practically $17.1 \%$ ( $v_{c}=30$ $\mathrm{m} / \mathrm{min})$ and $148.1 \%\left(v_{c}=120 \mathrm{~m} / \mathrm{min}\right)$. The increase of the cutting speed caused an increase when using the MQL system, or a decrease, when under the dry condition, in surface roughness values. In the conditions in which cooling/lubrication was employed, a larger number of scratches in the micro-machined surface were observed (Fig. 22) due to the tool probably slipping on the micromachined surface, as seen in Fig. 23. Furthermore, it was possible to observe the adherence of the micro-chips, in larger quantity, to the micro-machined surface when the MQL system was employed.

\subsection{Burr}

Figure 24 shows the comparison of the burr length in the dry and cooled/lubricated conditions. The increase of the feed rate caused an increase of burr length in $124.9 \%$ (dry) and $100.3 \%$ (MQL), on average. The increase of the cutting speed decreased the burr length in $48.5 \%$ (dry) and 65.8\% (MQL). When comparing the dry and cooled/lubricated conditions, the use of the MQL system caused a great reduction of the burr formation, $75.9 \%(f=10 \mu \mathrm{m} / \mathrm{rev})$ and $68.8 \%(f=$ $50 \mu \mathrm{m} / \mathrm{rev}$ ), on average. The reduction of the burr formation when employing the MQL system can be observed on Fig. 25. Figure 26 shows the Pareto chart for the burr formation. The magnitude of both parameters and their interaction were increased in relation to burr formation when employing the cooled/lubricated condition.

\section{Discussion}

This section debates the influence of cooling/lubrication in the micro-cutting process of the Ti-6Al-7Nb titanium alloy. The higher influence of the feed rate in all responses can be practically justified due to the relation between cutting depth and feed rate with the cutting area: the feed rate was the main influence on the responses because cutting depth was constant during the experiments. Thus, feed force was affected directly by the increase of cutting section due to the feed rate variation. Furthermore, a similar phenomenon should be considered in macro-turning as well, in which the feed rate is important for the changing of chip geometry; this changing occurs on long chips when low feed rates are used on small chips whilst higher feed rates are fixed.

When comparing the dry and the cooled/lubricated conditions, the results for the cutting speed of $30 \mathrm{~m} / \mathrm{min}$ were improved when the MQL system was employed. However, using the MQL system at the cutting speed of $120 \mathrm{~m} / \mathrm{min}$ resulted in negative impact or negligible improvement. The exception was the burr formation, which was strongly reduced when the cooled/lubricated 
condition was employed. Oliveira et al. [42] analysed the different cooled/lubricated systems during the micro-turning of a Ti-6Al-4V titanium alloy. The results indicated that the dry condition tends to improve surface roughness, whilst the MQL and air systems worsened the surface roughness, although the MQL system reduced the passive and feed forces. According to the authors, the temperature is higher in the dry condition than in cooled/lubricated conditions, which improves shear plane and chip formation.

According to Childs [43], the use of cutting fluids can influence differently low speeds (friction) and high speeds (thermal flow on the chip-tool contact area). It can be the reason for the cutting speed being more significant in the dry condition than in the MQL system, as observed in the Pareto charts; a similar relationship was also observed regarding cutting forces and the specific cutting energy. Cutting temperature is strongly influenced by cutting speed, and the increase of temperature can reduce cutting forces. Leppert [44] and Hadad and Sadeghi [45] observed that the MQL system was not efficient for cutting speeds higher than $100 \mathrm{~m} / \mathrm{min}$. According to Kajaria et al. [46], regarding the micro-droplet, only adhesion and centrifugal force are considered, neglecting the gravity effect and aerodynamic drag. If adhesion force is greater than centrifugal force, the micro-droplet adheres and spreads on the tool surface; otherwise, the micro-droplet separates from the tool surface due to a higher centrifugal force.

Simunovic et al. [47] did not observe differences between dry and wet conditions in their analysis of the surface roughness. The use of the MQL system presented prominent efficiency regarding burr formation. It occurs because the use of MQL produces a minimum burr due to the absence of build-up edge or a thermochemical reaction, when compared to flood and dry machining [46]. However, it should be noted that, in the micro-milling of Inconel 718, dry and MQL conditions presented no significant difference as to burr formation [48].

Considering the relationship between cutting edge radius and the undeformed chip thickness during a machining process, in this paper, the ratio $\mathrm{h} / \mathrm{re}$ was greater than 1 . Studying the ultraprecision machining, Yuan et al. [49] affirmed that the minimum chip thickness is round 0.2 to 0.4 of the radius of the cutting edge. Jaffery et al. [7] cited different ranges from minimum chip thickness and tool edge radius ratio, between 5 and 43\%, that depends to the elastic/plastic strain of the workpiece.

Based on these, considering this situation, according to Balogun et al. [50], a cutting mechanism tends to be value adding and sustainable machining. Thus, it can be considered that the elastic deformation of the workpiece during machining process decreased quickly and a perfect chip was generated. Moreover, the shearing phenomenon can be considered perfect because the ploughing effect did not occur and the increase of feed rate changed between the cutting mechanism from the rubbing/ploughing phenomenon and the shearing phenomenon. 
According to Singaravel and Selvaraj [51], the main cutting force components have higher magnitude than feed force and radial force components as occurred in the experimental tests detailed by this paper. Thus, it can be considered that the main cutting force decreased at high cutting speed and that this phenomenon occurs due to the high cutting speed increasing the shear angle and thus generating a minimum shear plane area. The simultaneous increase of cutting speed and feed rate provides an increase of the contact area between the cutting tool and workpiece.

Figure 27 shows the influence comparison of the cooling/ lubrication when using minimum quantity lubrication (MQL), high-speed machining (HSM) and both techniques, although the average of the response analysed in this study. The HSM system provided similar or better results than the MQL system. Regarding the response used for identification of the ploughing effect, like the Lee-Shaffer shear plane angle model, the employment of HSM was better than MQL's and both techniques jointly. Besides, considering chip compression ratio, the use of MQL was disadvantageous. Thus, when possible, the use of HSM — solely — can be more advantageous than the use of the MQL system itself for orthogonal micro-cutting of the Ti-6Al-7Nb titanium alloyfor all criteria analysed in this study, except burr formation.

\section{Conclusions}

Based on the results of sustainable techniques in the orthogonal micro-cutting process for the Ti-6Al-7Nb titanium alloy, the main conclusions drawn from the study are the following:

Regarding cutting forces (thrust, cutting and machining), the use of the MQL system reduced the magnitude of these \& forces only under low cutting speed. However, the combination of HSM and MQL systems increased the magnitude of these cutting forces.

It should be noted that, generally, the analysis of cutting forces is studied based on a static analysis taking into account the maximum peak. But in this article, the innovation was based on a dynamic analysis analysing point-to-point, employing a high acquisition rate.

When analysing the specific cutting energy, using the MQL system was efficient for all conditions. However, the use of MQL did not result in good performance for the friction coefficient and shear angle plane when combined with the HSM system. Furthermore, the study carried out in this paper also analysed the influence of the cutting fluid on the ploughing effect.

Regarding the analysis of the chip, its compression ratio and its morphology, greater results were obtained with the use of HSM, whilst the use of MQL caused worse results independently of the cutting speed. 
Regarding the quality of the micro-machined surface, the use of MQL provided increase in surface roughness due to the high adherence of micro-chips and the slipping of the tool during cutting, although the MQL system was responsible for the great reduction in burr formation.

Finally, the material is a new titanium alloy that needs more studies, once it is necessary to know the machined surface of this biomaterial to avoid the damage in osseointegration or sharp corrosion.

\section{Acknowledgements}

The authors would like to thank TiFast S.R.L., from Italy, and Sandvik Coromant ${ }^{\mathrm{TM}}$, from Portugal. Additional thanks to the Ministry of Education's Coordination for the Improvement of Higher Education Personnel (CAPES); Foundation for Science and Technology (FCT), Portugal (Project No. 031556-FCT/02/SAICT/2017; FAMASI - Sustainable and intelligent manufacturing by machining, financed by FCT/POCI); and the State of Minas Gerais Research Foundation (FAPEMIG; project number APQ-01987-14) by their financial support.

\section{References}

[1] Masuzawa T (2000) State of the art of micromachining. Ann ClRP 49:473-488. https://doi.org/10.1016/S0007-8506(07)63451-9

[2] Câmara MA, Rubio JCC, Abrão AM, Davim JP (2012) State of the art on micromilling of materials , a review. J Mater Sci Technol 28: 673-685. https://doi.org/10.1016/S1005$\underline{0302(12) 60115-7}$

[3] Lauro CH, Brandão LC, Panzera TH, Davim JP (2015) Surface integrity in the micromachining. Rev Adv Mater Sci 40:227-234

[4] Cardoso P, Davim JP (2010) Optimization of surface roughness in micromilling. Mater Manuf Process 25:1115-1119. https://doi.org/ 10.1080/10426914.2010.481002

[5] Bodziak S, de Souza AF, Rodrigues AR et al (2014) Surface integrity of moulds for microcomponents manufactured by micromilling and electro-discharge machining. J Braz Soc Mech Sci Eng 36: 623-635. https://doi.org/10.1007/s40430-013-0108-9

[6] Afazov SM, Zdebski D, Ratchev SM, Segal J, Liu S (2013) Effects of micro-milling conditions on the cutting forces and process stability. J Mater Process Technol 213:671-684. https://doi.org/10. 1016/j.jmatprotec.2012.12.001

[7] Jaffery SHI, Khan M, Ali L, Mativenga PT (2016) Statistical analysis of process parameters in micromachining of Ti-6Al-4V alloy. Proc Inst Mech Eng B J Eng Manuf 230:1017-1034. https://doi. org/10.1177/0954405414564409 
[8] Chae J, Park SS, Freiheit T (2006) Investigation of micro-cutting operations. Int J Mach Tools Manuf 46:313-332. https://doi.org/10. 1016/j.ijmachtools.2005.05.015

[9] de Oliveira FB, Rodrigues AR, Coelho RT, de Souza AF (2015) Size effect and minimum chip thickness in micromilling. Int J Mach Tools Manuf 89:39-54. https://doi.org/10.1016/j.ijmachtools.2014. 11.001

[10]Ng CK, Melkote SN, Rahman M, Kumar AS (2006) Experimental study of micro- and nanoscale cutting of aluminum 7075-T6. Int J Mach Tools Manuf 46:929-936. https://doi.org/10.1016/j. ijmachtools.2005.08.004

[11] Bissacco G, Hansen HN, De Chiffre L (2005) Micromilling of hardened tool steel for mould making applications. J Mater Process Technol 167:201-207. https://doi.org/10.1016/j. jmatprotec.2005.05.029

[12] Jagadesh T, Samuel GL (2014) Investigations into cutting forces and surface roughness in micro turning of titanium alloy using coated carbide tool. Procedia Mater Sci 5:2450-2457. https://doi. org/10.1016/j.mspro.2014.07.496

[13]Ducobu F, Rivière-Lorphèvre E, Filippi E (2016) Experimental and numerical investigation of the uncut chip thickness reduction in Ti6Al4V orthogonal cutting. Meccanica 52:1-16. https://doi.org/ 10.1007/s11012-016-0499-7

[14]Bhanot N, Rao PV, Deshmukh SG (2015) Sustainable manufacturing: an interaction analysis for machining parameters using graph theory. Procedia Soc Behav Sci 189:57-63. https://doi.org/10.1016/ j.sbspro.2015.03.192

[15]Chetan, Ghosh S, Rao PV (2015) Application of sustainable techniques in metal cutting for enhanced machinability: a review. J Clean Prod 100:17-34. https://doi.org/10.1016/j.jclepro.2015.03. 039

[16]Carou D, Rubio EM, Davim JP (2015) A note on the use of the minimum quantity lubrication (MQL) system in turning. Ind Lubr Tribol 67:256-261. https://doi.org/10.1108/ILT-07$\underline{2014-0070}$

[17]Pusavec F, Deshpande A, Yang S, M'Saoubi R, Kopac J, Dillon OW Jr, Jawahir IS (2014) Sustainable machining of high temperature nickel alloy - Inconel 718: part 1 - predictive performance models. J Clean Prod 81:255-269. https://doi.org/10.1016/j. jclepro.2014.06.040

[18]Rabiei F, Rahimi AR, Hadad MJ, Ashrafijou M (2015) Performance improvement of minimum quantity lubrication (MQL) technique in surface grinding by modeling and optimization. J Clean Prod 81:447-460. https://doi.org/10.1016/j.jclepro. 2014.08.045

[19] Al-Ghamdi KA, Iqbal A (2015) A sustainability comparison between conventional and highspeed machining. J Clean Prod 108: 192-206. https://doi.org/10.1016/j.jclepro.2015.05.132 
[20]Li KM, Chou SY (2010) Experimental evaluation of minimum quantity lubrication in near micro-milling. J Mater Process Technol 210:2163-2170. https://doi.org/10.1016/j.jmatprotec. $\underline{2010.07 .031}$

[21]Fang FZ, Liu YC (2004) On minimum exit-burr in micro cutting. J Micromech Microeng 14:984-988. https://doi.org/10.1088/09601317/14/7/020

[22] Baldo D, Ribeiro Filho SLM, Lauro CH et al (2015) Analysis of surface roughness in micro milling of Ti-6Al-4V titanium alloy. Adv Mater Res 1079-1080:3-6. https://doi.org/10.4028/www. scientific.net/AMR.1079-1080.3

[23]Cheng K (2009) Machining dynamics - Fundamentals, applications and practices. https://doi.org/10.1007/978-1-84628-368-0

[24]Trent E, Wright P (2000) Metal Cutting, 4th edn. Butterworth- Heinemann, Woburn

[25] Guohe L, Cai Y, Bing Y (2010) Experimental study of adiabatic shear critical conditions in orthogonal cutting of AISI 1045 steel. In: 2010 Int. Conf. Electr. Control Eng. IEEE, pp 948-951

[26]Ducobu F, Rivière-Lorphèvre E, Filippi E (2016) Material constitutive model and chip separation criterion influence on the modeling of Ti6Al4V machining with experimental validation in strictly orthogonal cutting condition. Int J Mech Sci 107:136-149. https:// doi.org/10.1016/j.ijmecsci.2016.01.008

[27]Liao Z, Axinte DA (2016) On chip formation mechanism in orthogonal cutting of bone. Int J Mach Tools Manuf 102:41-55. https:// doi.org/10.1016/j.ijmachtools.2015.12.004

[28] Fromentin G, Gasparoux J, Agbeviade K, Giovanola JH (2016) Development of a precision machine to perform and study orthogonal micro-cutting. Prod Eng 10:217-226. https://doi.org/10.1007/ s11740-016-0657-8

[29]Liu K, Melkote SN (2007) Finite element analysis of the influence of tool edge radius on size effect in orthogonal micro-cutting process. Int $\mathrm{J}$ Mech Sci 49:650-660. https://doi.org/10.1016/j.ijmecsci. 2006.09.012

[30] Schneider F, Bischof R, Kirsch B, Kuhn C, Müller R, Aurich JC (2016) Investigation of Chip formation and surface integrity when micro-cutting cp-titanium with ultra-fine grain cemented carbide. Procedia CIRP 45:115-118. https://doi.org/10.1016/j.procir.2016. 02.257

[31]Bergmann CP, Stumpf A (2013) Dental ceramics - Microstructure, properties and degradation. https://doi.org/10.1007/978-3-64238224-6

[32]Niinomi M (1998) Mechanical properties of biomedical titanium alloys. Mater Sci Eng A 243:231-236. https://doi.org/10.1016/ S0921-5093(97)00806-X

[33] Geetha M, Singh AK, Asokamani R, Gogia AK (2009) Ti based biomaterials, the ultimate choice for orthopaedic implants - a review. Prog Mater Sci 54:397-425. https://doi.org/10.1016/j. pmatsci.2008.06.004 
[34]Datta S, Mahfouf M, Zhang Q, Chattopadhyay PP, Sultana N (2016) Imprecise knowledge based design and development of titanium alloys for prosthetic applications. J Mech Behav Biomed Mater 53:350-365. https://doi.org/10.1016/j.jmbbm.2015.08.039

[35] Wang K (1996) The use of titanium for medical applications in the USA. Mater Sci Eng A 213:134-137. https://doi.org/10.1016/ 0921-5093(96)10243-4

[36]Bolzoni L, Ruiz-Navas EM, Neubauer E, Gordo E (2012) Mechanical properties and microstructural evolution of vacuum hot-pressed titanium and Ti-6Al-7Nb alloy. J Mech Behav Biomed Mater 9:91-99. https://doi.org/10.1016/J.JMBBM.2012.01.015

[37] Santos PF, Niinomi M, Liu H, Cho K, Nakai M, Itoh Y, Narushima T, Ikeda M (2016) Fabrication of low-cost beta-type Ti-Mn alloys for biomedical applications by metal injection molding process and their mechanical properties. J Mech Behav Biomed Mater 59:497- 507. https://doi.org/10.1016/j.jmbbm.2016.02.035

[38]Engineering Village (2018) Number of paper about Titanium, pure and some alloys. https://www.engineeringvillage.com. Accessed 29 May 2018

[39]Bütev E, Esen Z, Bor Ş (2016) Characterization of Ti6Al7Nb alloy foams surface treated in aqueous $\mathrm{NaOH}$ and $\mathrm{CaCl} 2$ solutions. J Mech Behav Biomed Mater 60:127-138. https://doi.org/10.1016/j.jmbbm.2015.12.040

[40] Schueler GM, Engmann J, Marx T, Haberland R, Aurich JC (2010) Burr formation and surface characteristics in micro-end milling of titanium alloys. In: Aurich JC, Dornfeld D (eds) Burrs - anal. Control Remov. Springer Berlin Heidelberg, Heidelberg, pp 129- 138

[41]Lauro CH, Ribeiro Filho SLM, Brandão LC, Davim JP (2016) Analysis of behaviour biocompatible titanium alloy (Ti-6Al-7Nb) in the micro-cutting. Measurement 93:529-540

[42] de Oliveira JA, Ribeiro Filho SLM, Lauro CH, Brandão LC (2017) Analysis of the micro turning process in the Ti-6Al-4V titanium alloy. Int J Adv Manuf Technol 92:4009-4016. https://doi.org/10. 1007/s00170-017-0449-0

[43]Childs THC (2006) Friction modelling in metal cutting. Wear 260: 310-318. https://doi.org/10.1016/j.wear.2005.01.052

[44]Leppert T (2011) Effect of cooling and lubrication conditions on surface topography and turning process of C45 steel. Int J Mach Tools Manuf 51:120-126. https://doi.org/10.1016/j.jjmachtools. 2010.11.001

[45] Hadad M, Sadeghi B (2013) Minimum quantity lubrication-MQL turning of AISI 4140 steel alloy. J Clean Prod 54:332-343. https:// doi.org/10.1016/j.jclepro.2013.05.011

[46]Kajaria S, Chittipolu S, Adera S, Hung WN (2012) Micromilling in minimum quantity lubrication. Mach Sci Technol 16:524-546. https://doi.org/10.1080/10910344.2012.730848 
[47] Simunovic K, Simunovic G, Saric T (2015) Single and multiple goal optimization of structural steel face milling process considering different methods of cooling/lubricating. J Clean Prod 94:321- 329. https://doi.org/10.1016/j.jclepro.2015.02.015

[48]Ucun I, Aslantas K, Bedir F (2014) The effect of minimum quantity lubrication and cryogenic pre-cooling on cutting performance in the micro milling of Inconel 718. Proc Inst Mech Eng B J Eng Manuf 229:2134-2143. https://doi.org/10.1177/0954405414546144

[49] Yuan ZJ, Zhou M, Dong S (1996) Effect of diamond tool sharpness on minimum cutting thickness and cutting surface integrity in ultraprecision machining. J Mater Process Technol 62:327-330. https://doi.org/10.1016/S0924-0136(96)02429-6

[50]Balogun VA, Edem IF, Adekunle AA, Mativenga P (2016) Specific energy based evaluation of machining efficiency. J Clean Prod 116: 187-197. https://doi.org/10.1016/j.jclepro.2015.12.106

[51] Singaravel B, Selvaraj T (2016) Experimental investigation on cutting forces, specific cutting pressure, co-efficient of friction and shear energy in turning of hsla steel. Manage Prod Eng Rev 7:71- 76. https://doi.org/10.1515/mper-2016-0008 


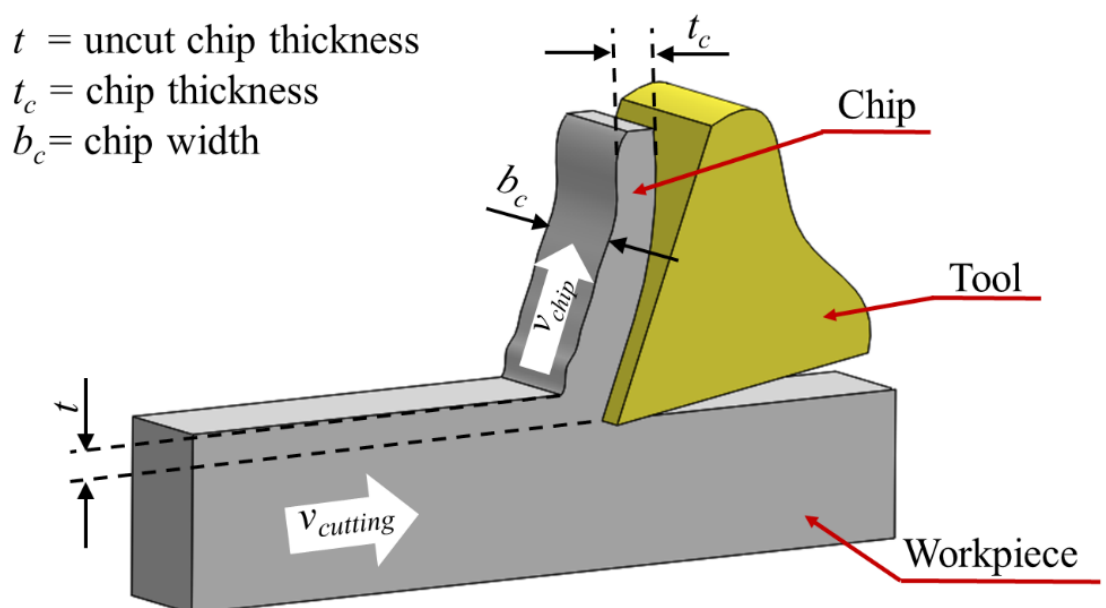

Figure 1 - Schematic of orthogonal cutting

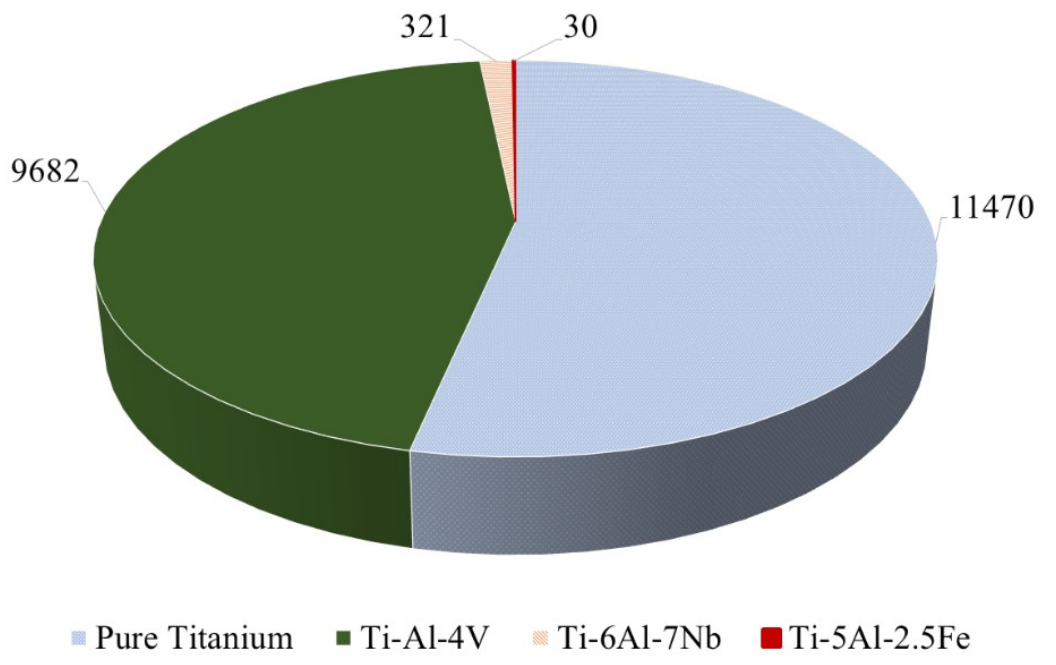

Figure 2 - Number of papers about titanium and their alloy between 2001 and 2016 in the Engineering Village database (2016)

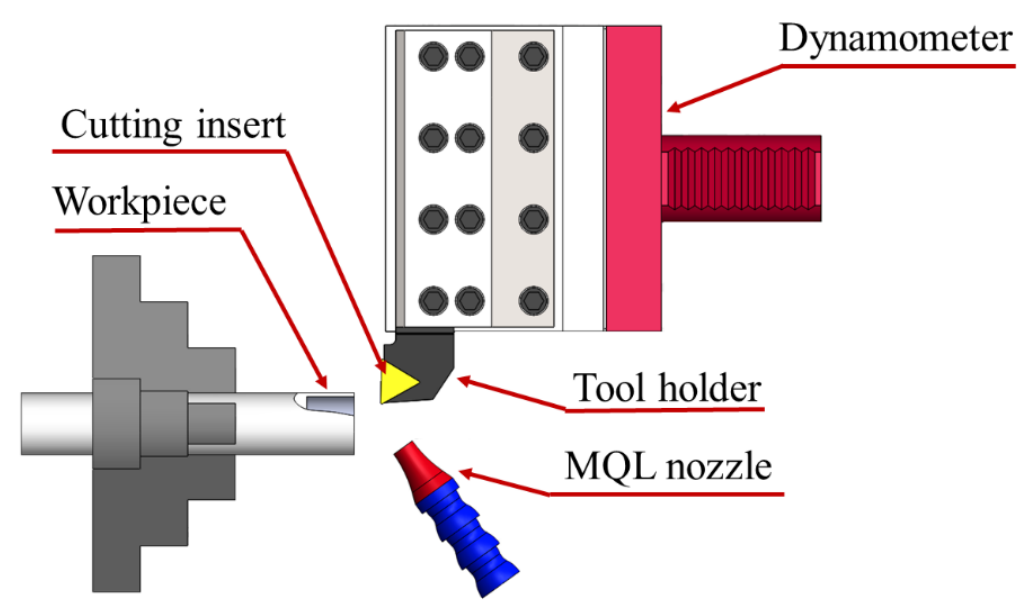

Figure 3 - Experimental set-up for use of the MQL in the micro-cutting 


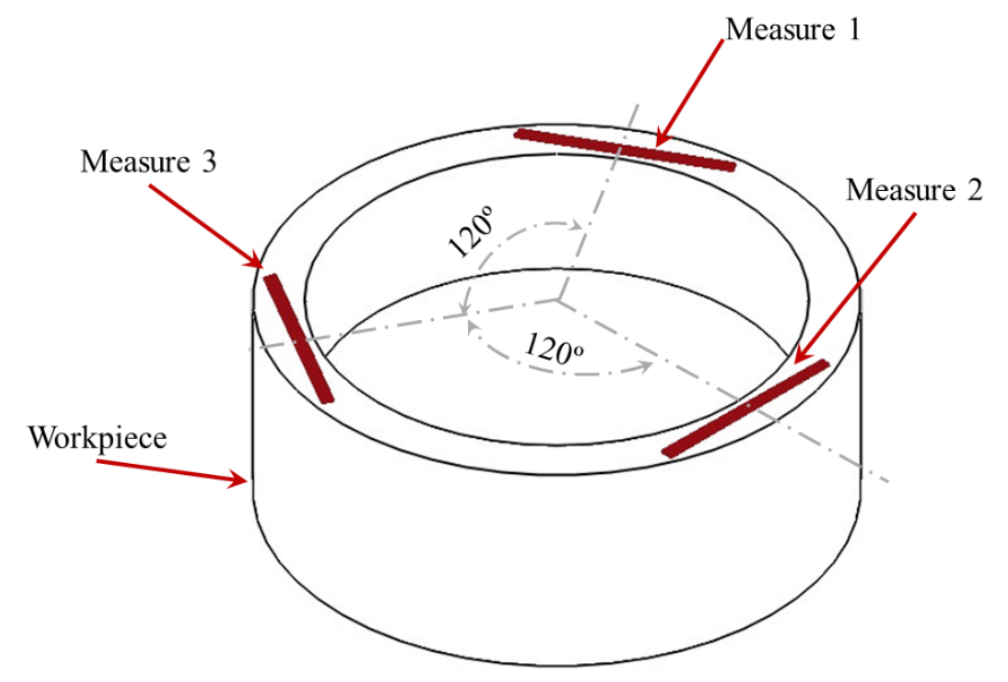

Figure 4 - Surface roughness measures diagram of the micro-cutting tests

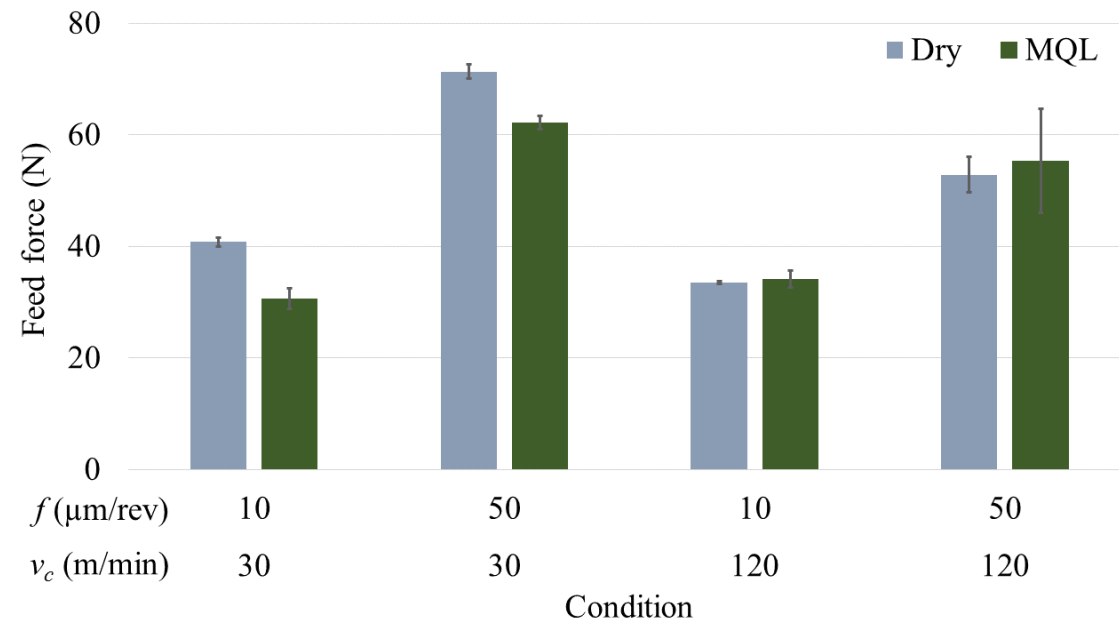

Figure 5 - Comparison of $F_{T}$ forces in the dry and cooling/lubricated micro-cutting 


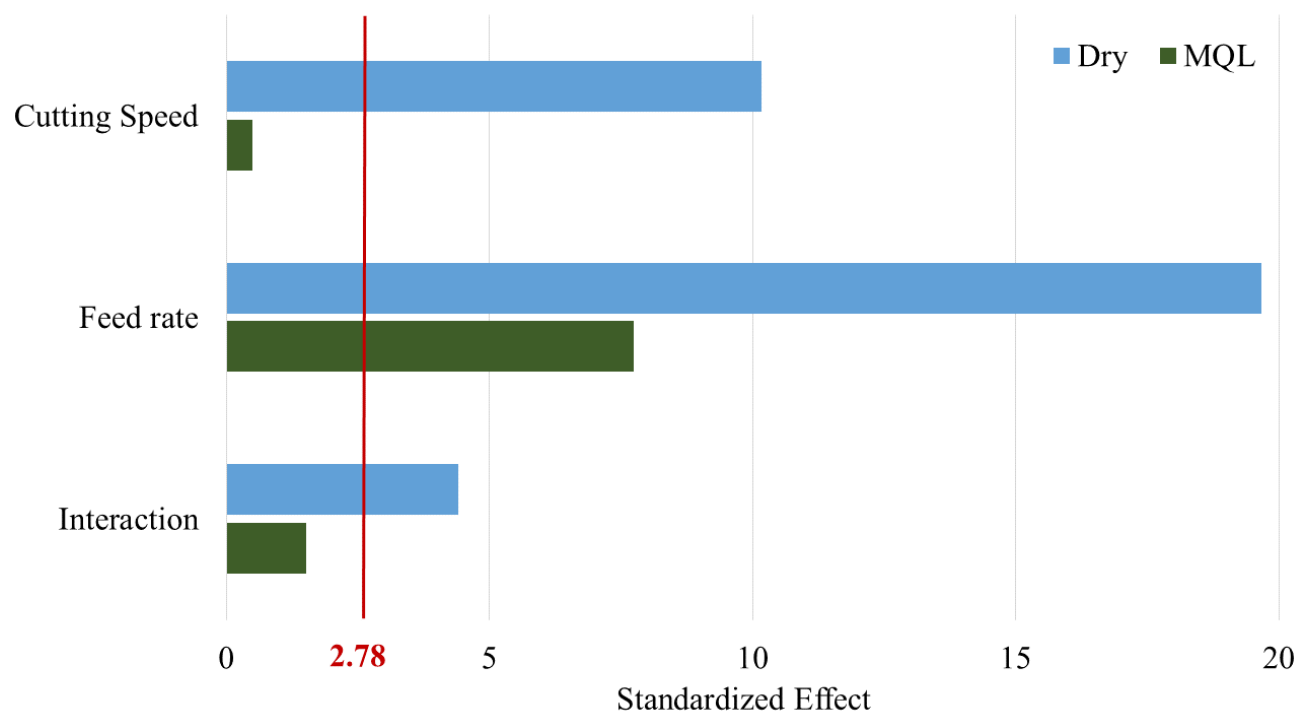

Figure 6 - Effect Pareto chart for the $F_{T}$ forces in the micro-cutting tests

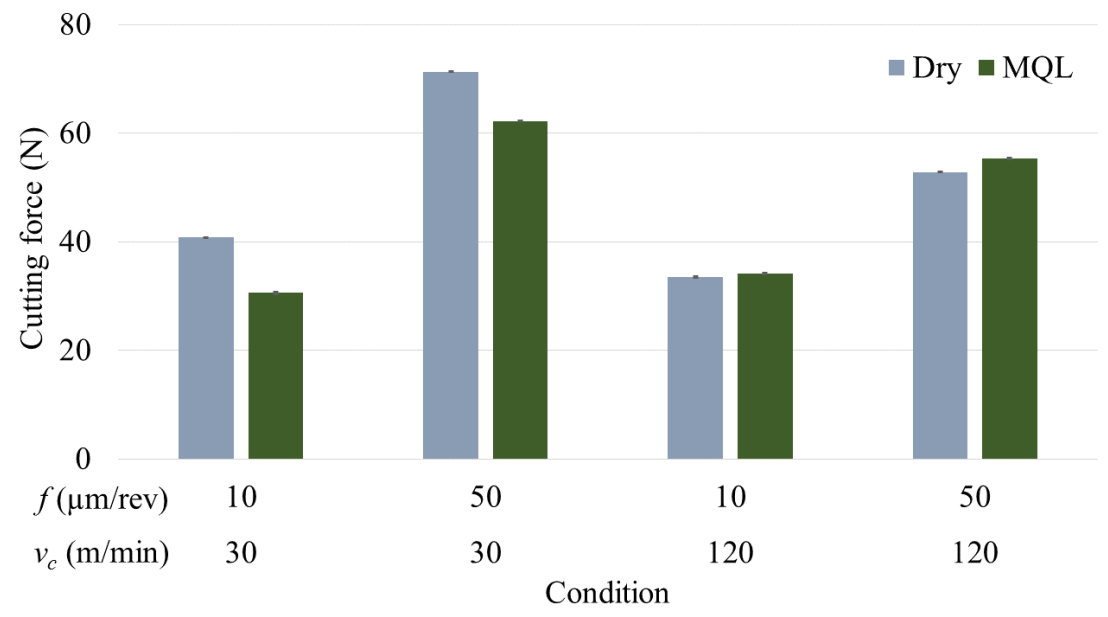

Figure 7 - Comparison of $F_{C}$ forces in the dry and cooling/lubricated micro-cutting 


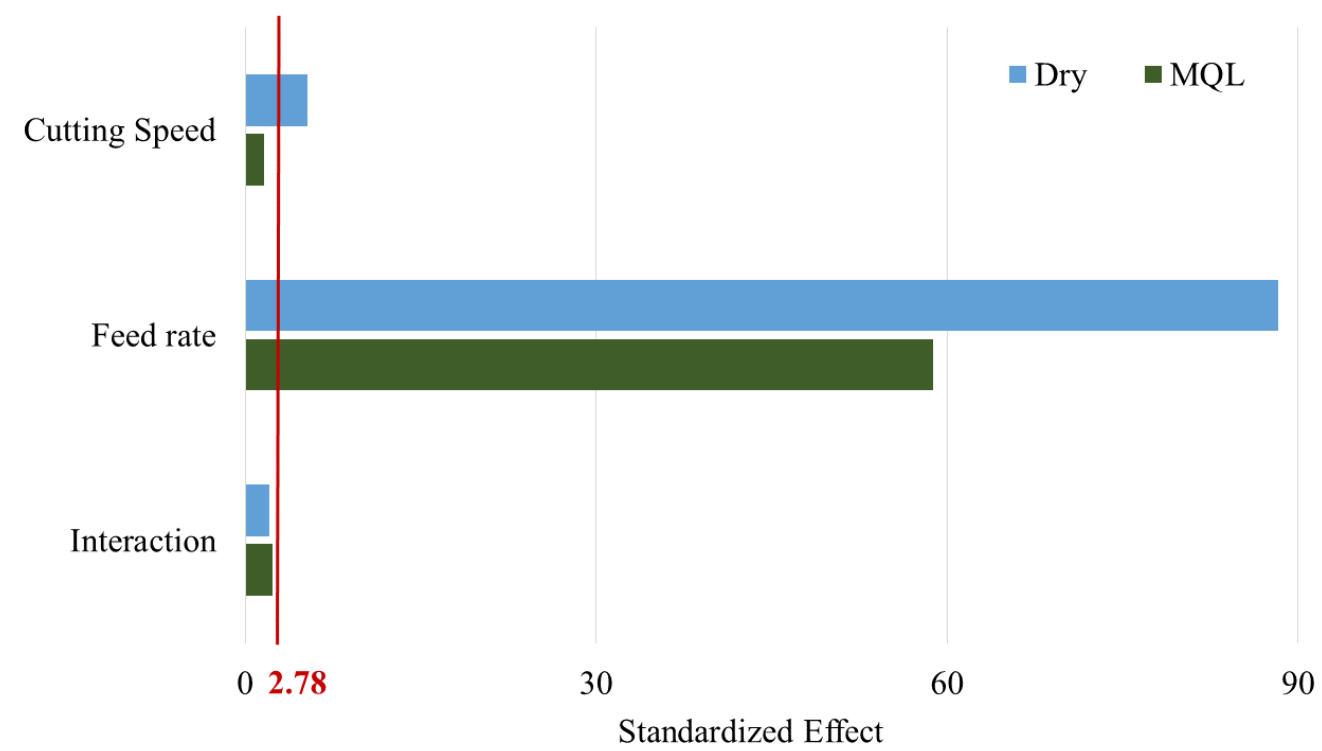

Figure 8 - Effect Pareto chart for the $F_{C}$ forces in the micro-cutting tests

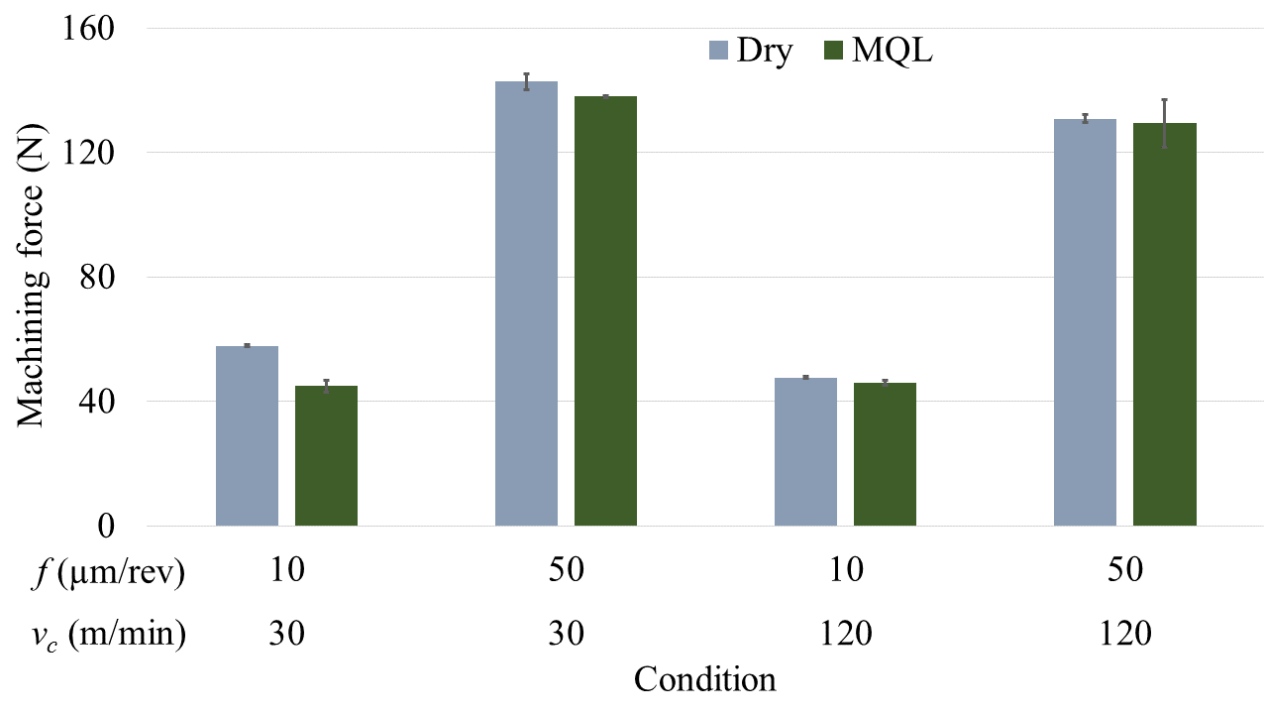

Figure 9 - Comparison of the $F_{R}$ forces in the dry and cooling/lubricated micro-cutting 


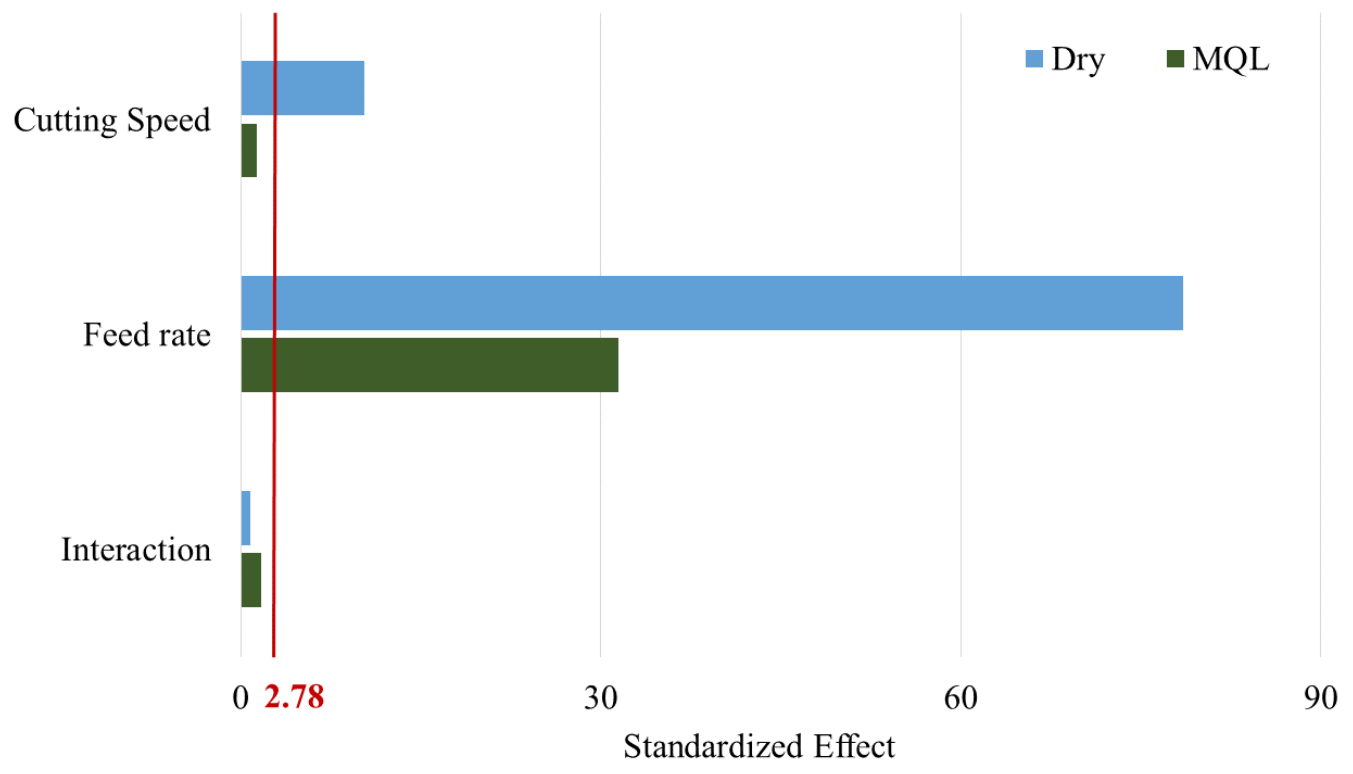

Figure 10 - Effect Pareto chart for the $F_{R}$ forces in the micro-cutting tests

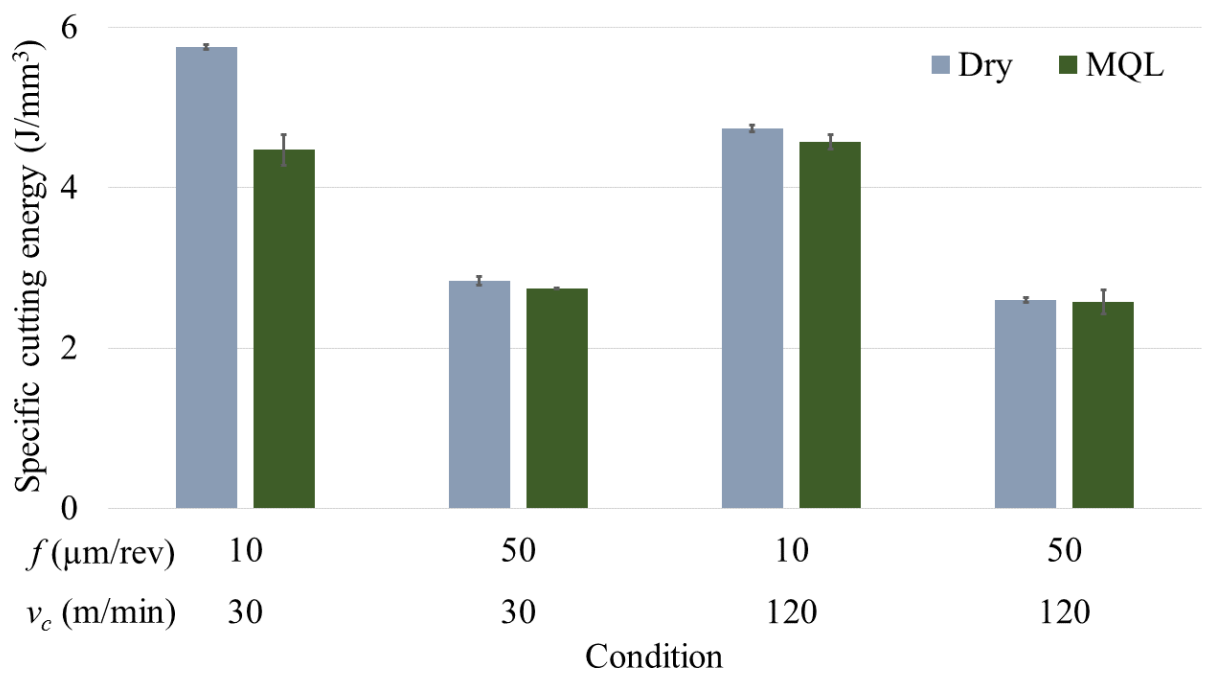

Figure 11 - Comparison of the specific cutting energy in the dry and cooling/lubricated micro-cutting 


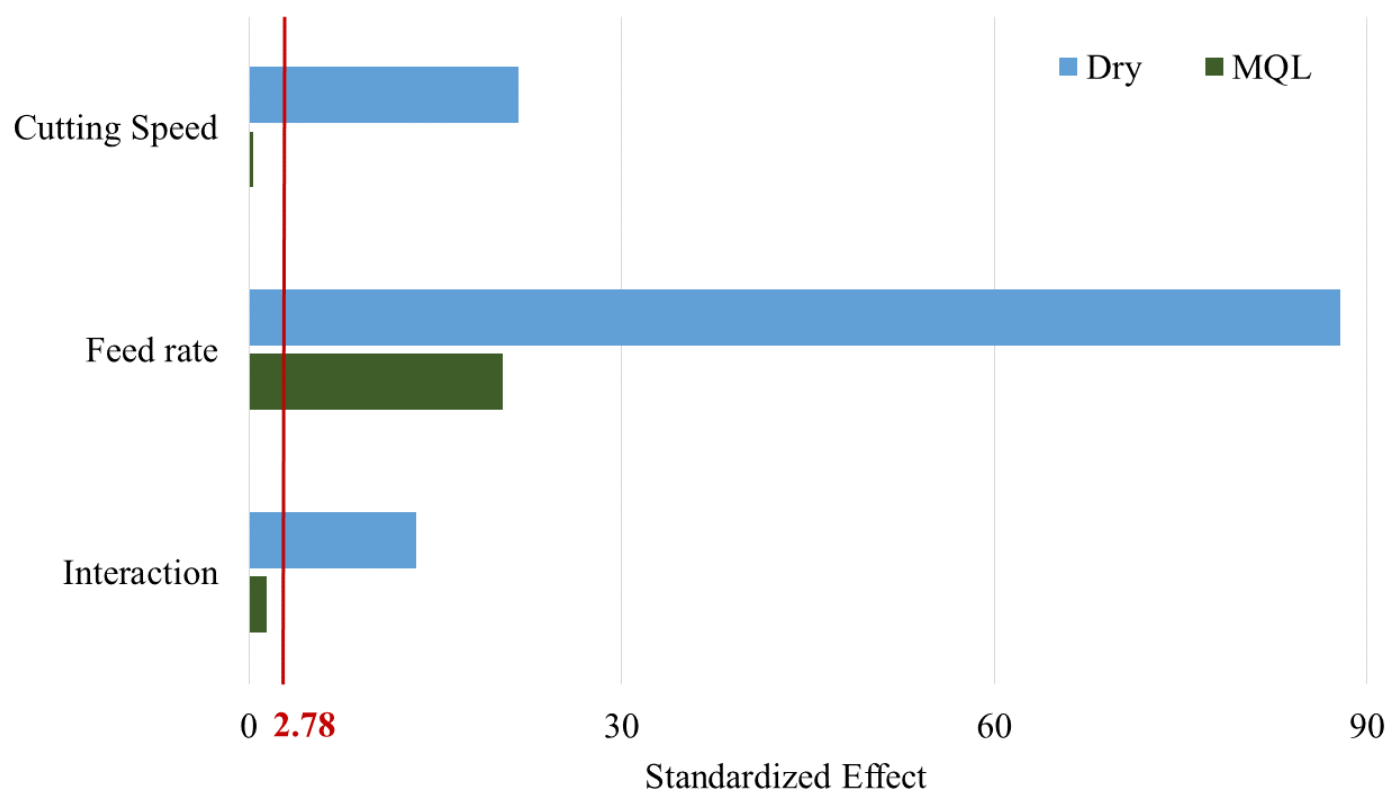

Figure 12 - Effect Pareto chart for the specific cutting energy in the micro-cutting tests

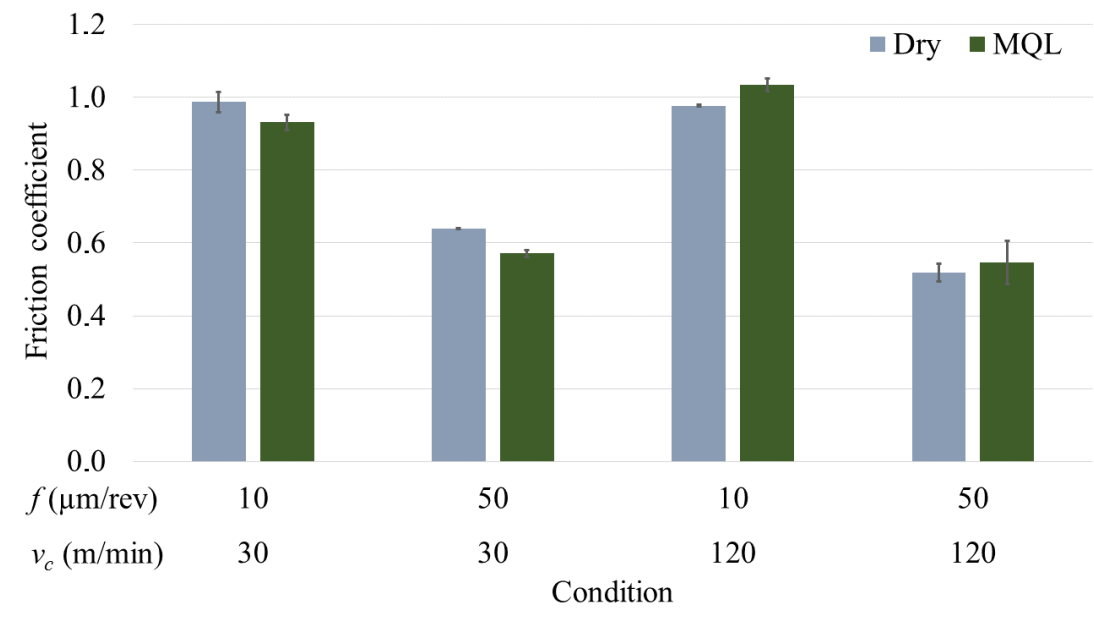

Figure 13 - Comparison of the friction coefficient in in the dry and cooling/lubricated micro-cutting 


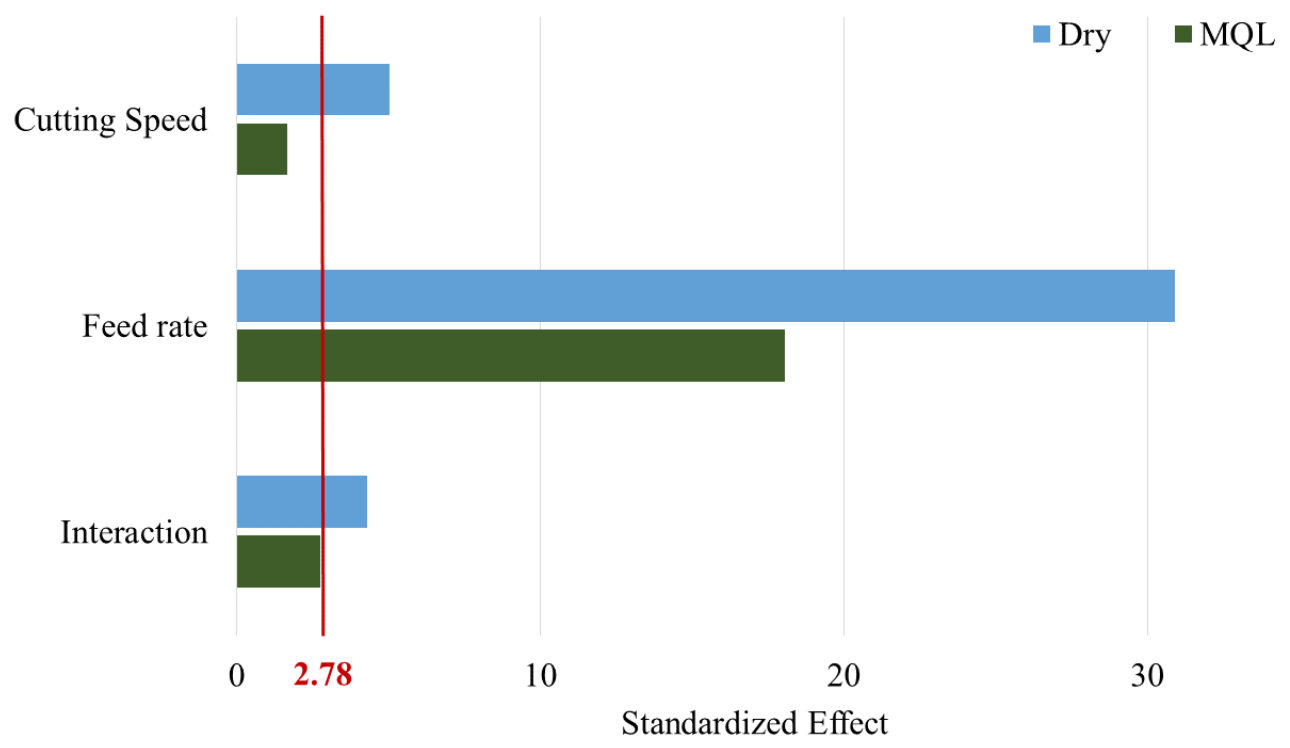

Figure 14 - Effect Pareto chart for the friction coefficient in the micro-cutting tests

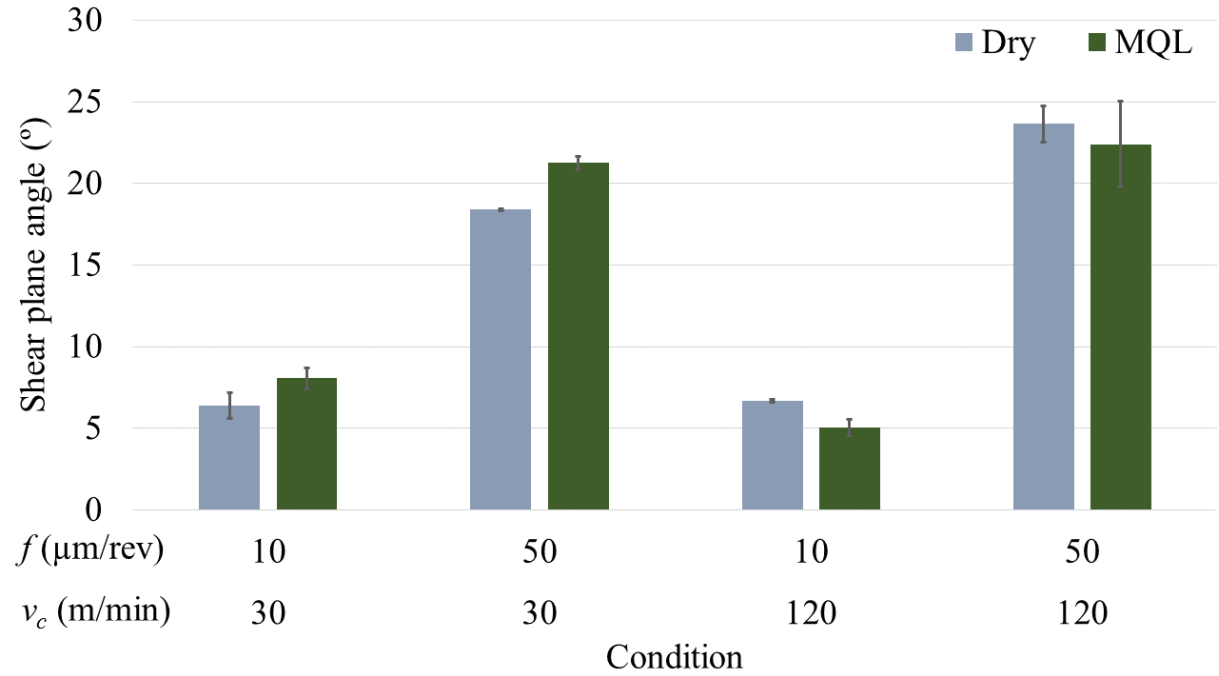

Figure 15 - Comparison of the Lee - Shaffer shear plane angle in the dry and cooling/lubricated micro-cutting 


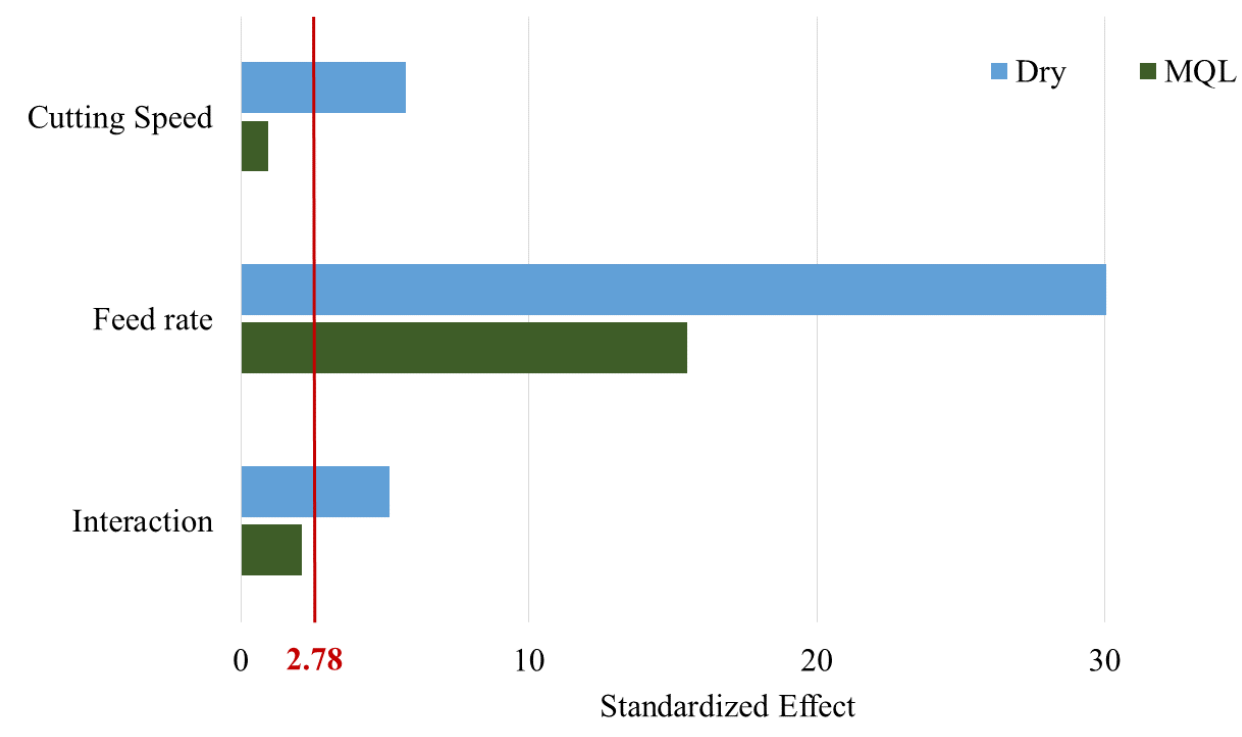

Figure 16 - Effect Pareto chart for the Lee - Shaffer shear plane angle in the micro-cutting tests

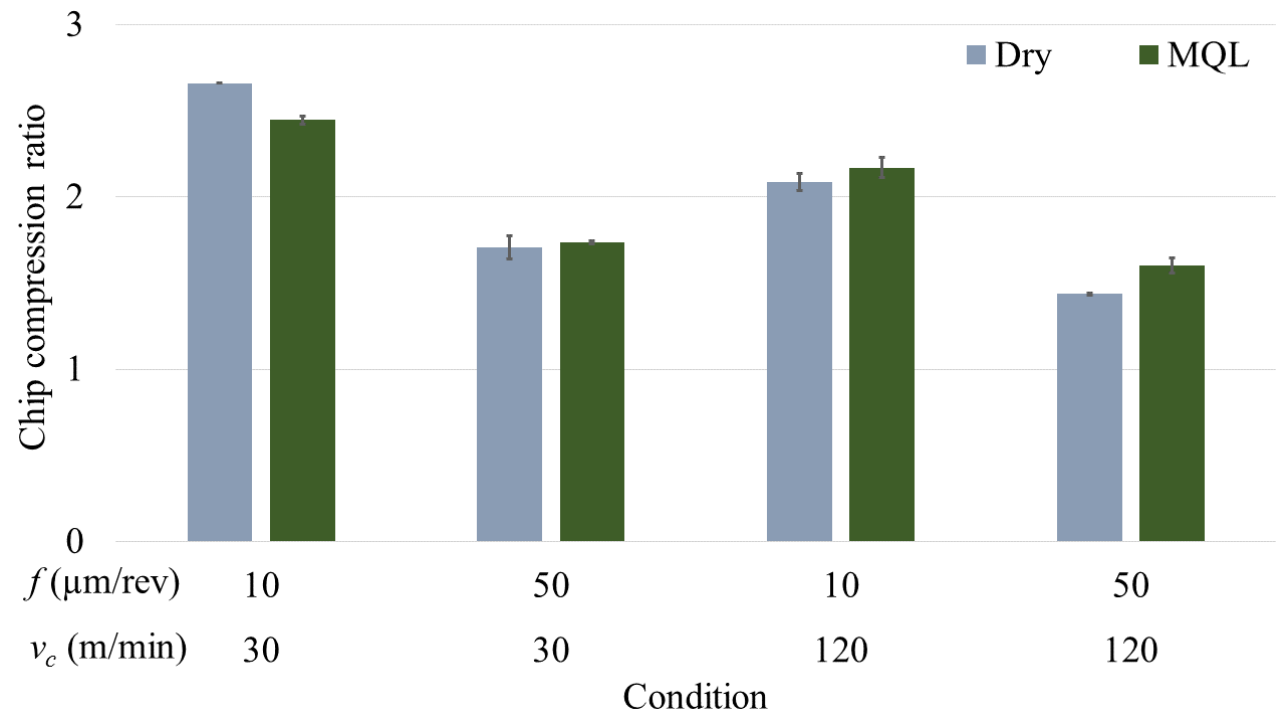

Figure 17 - Comparison of chip compression ratio in the dry and cooling/lubricated micro-cutting 


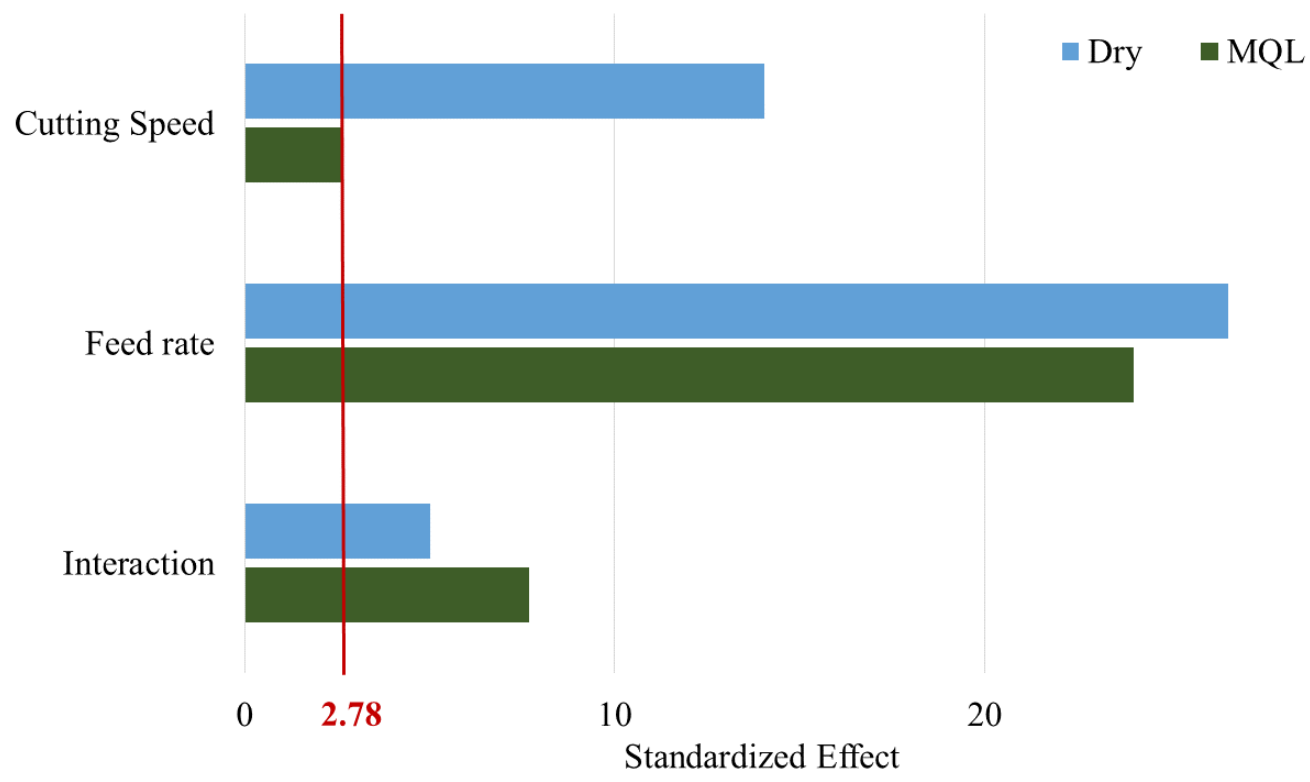

Figure 18 - Effect Pareto chart for the chip compression ratio in the micro-cutting tests

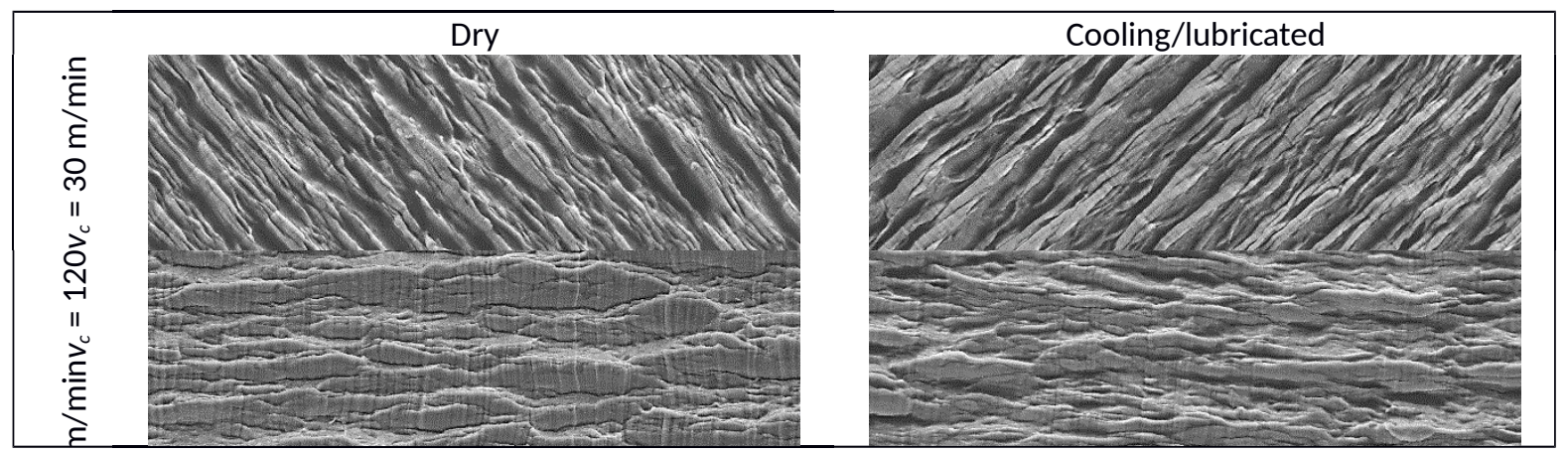

Figure 19 - Chip morphology in the micro-cutting tests for the $f=10 \mu \mathrm{m} / \mathrm{rev}$

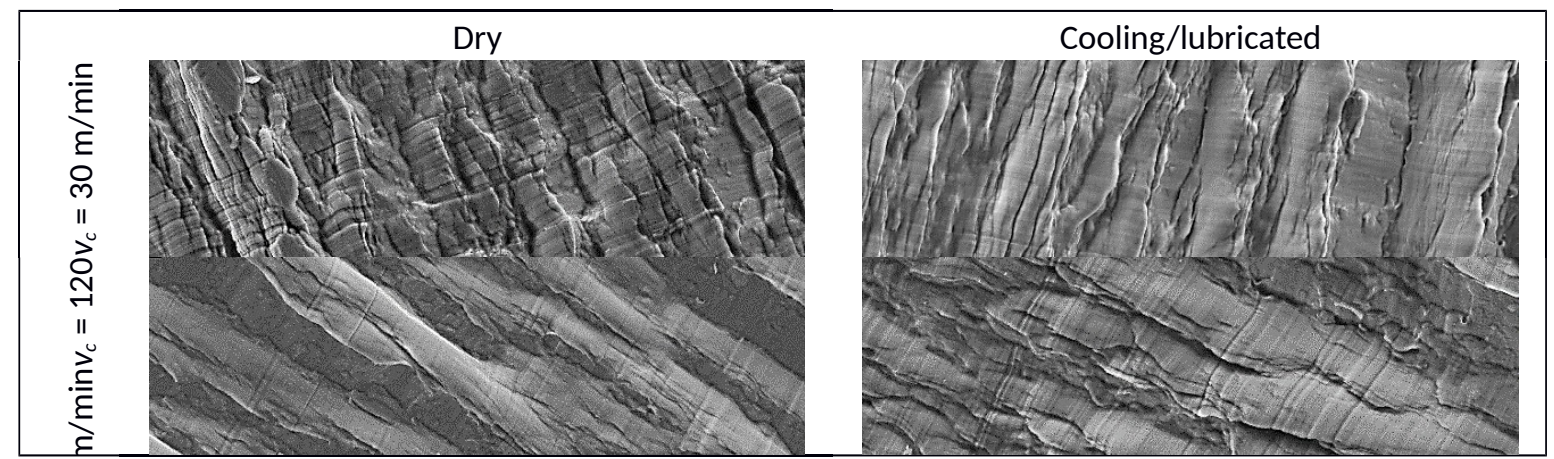

Figure 20 - Chip morphology in the micro-cutting tests for the $f=50 \mu \mathrm{m} / \mathrm{rev}$ 


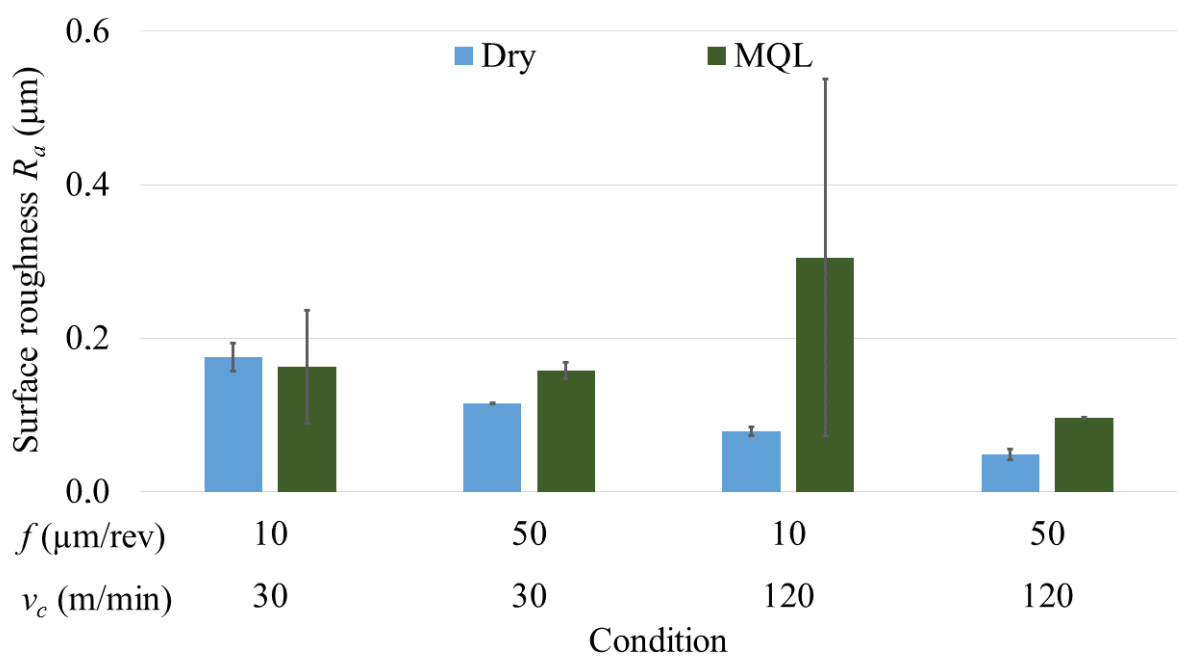

a) Values of $R_{a}$ surface roughness in the micro-cutting

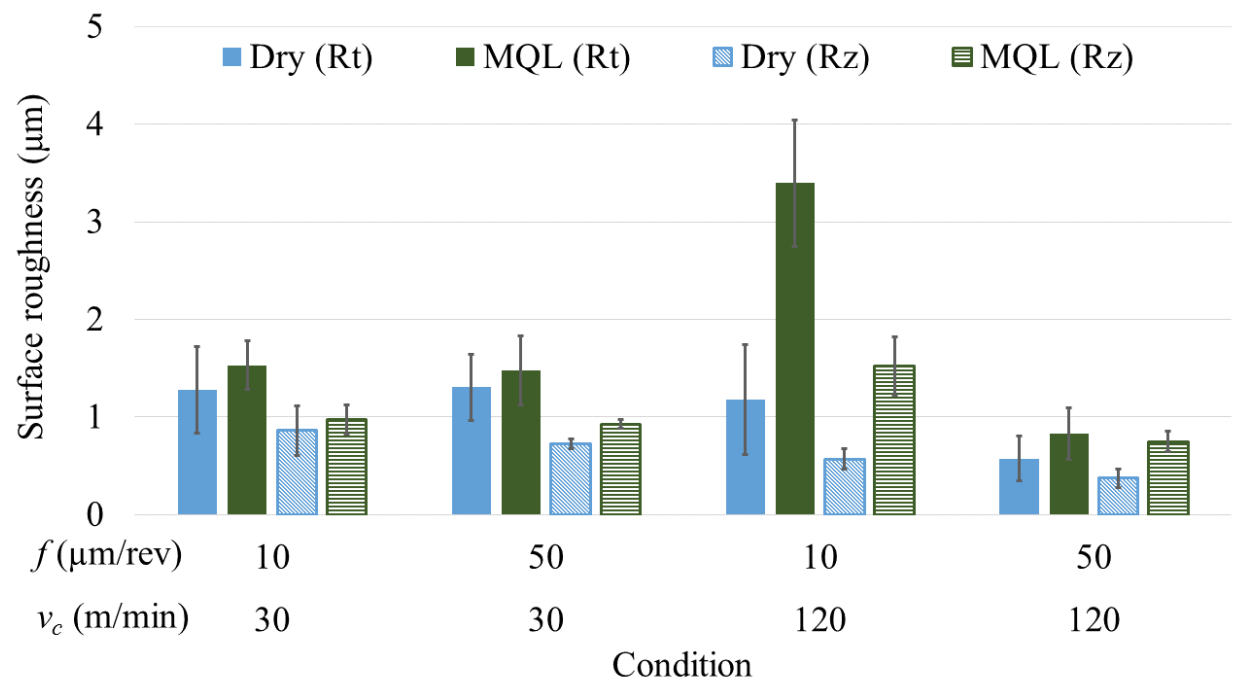

b) Values of $R_{t}$ and $R_{z}$ surface roughness in the micro-cutting

Figure 21 - Comparison of surface roughness in the dry and cooling/lubricated micro-cutting 


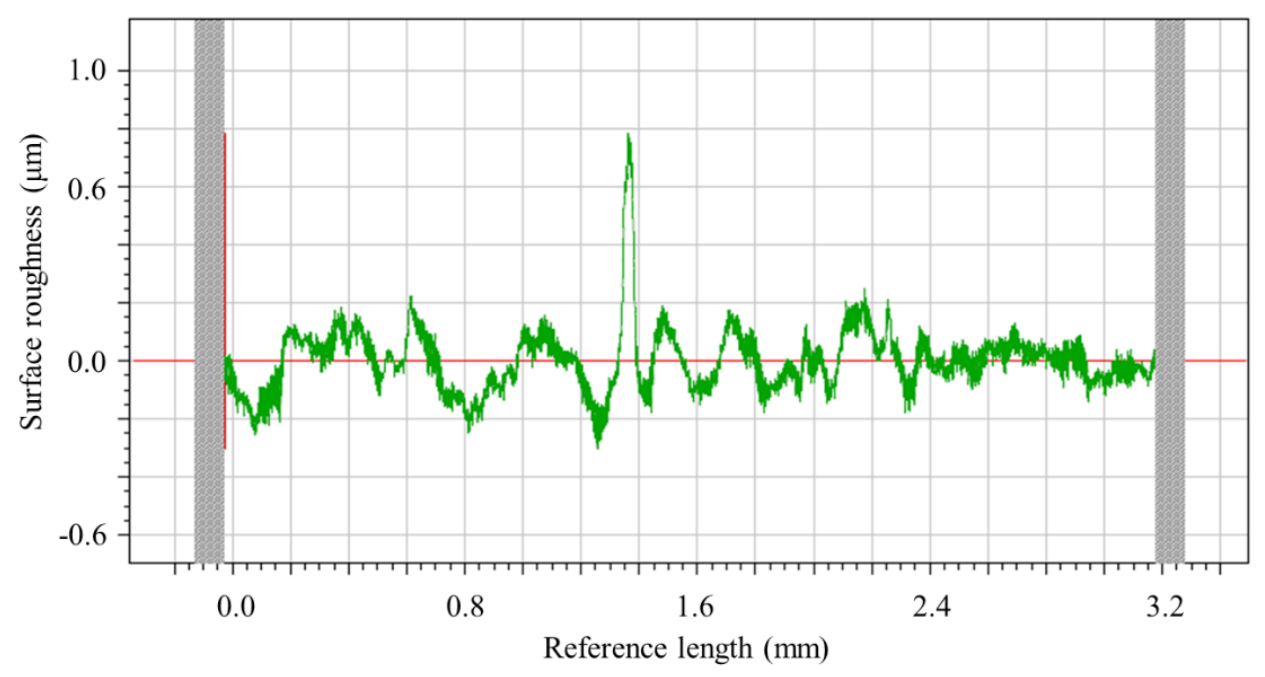

a) Dry condition

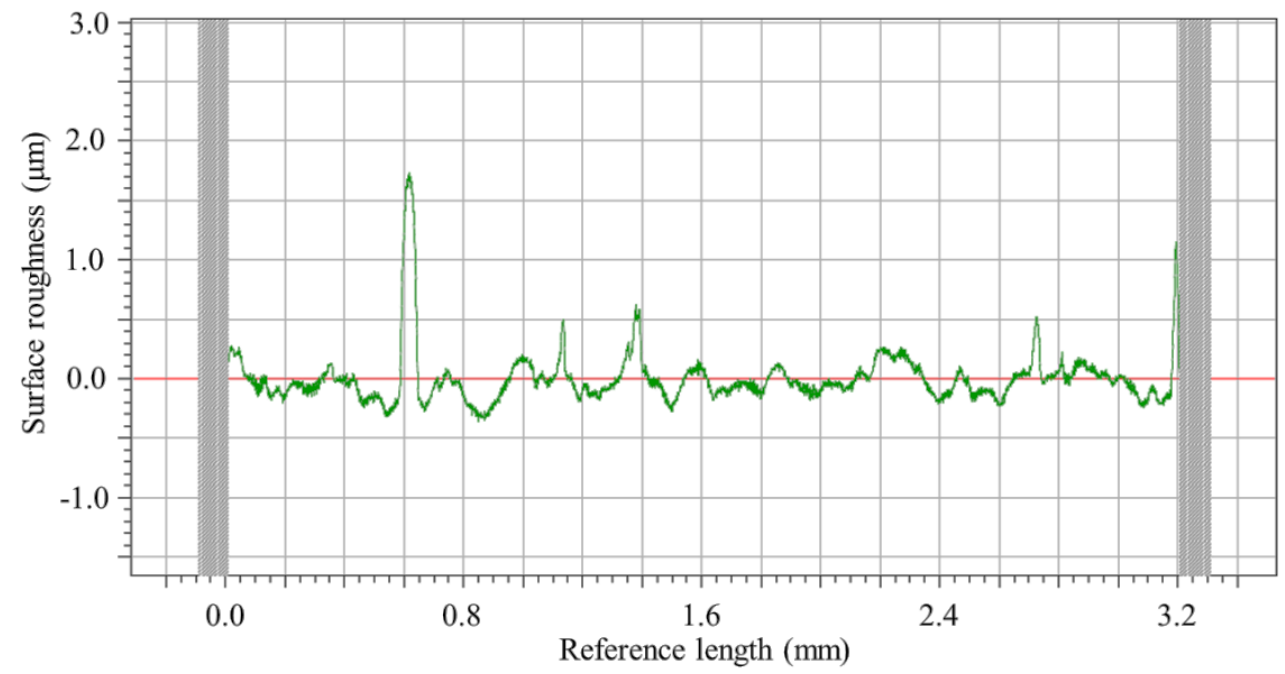

b) Cooling/lubricated condition

Figure 22 - Example of the surface roughness outline in the micro-cutting $\left(v_{c}=120 \mathrm{~m} / \mathrm{min}\right.$ and $\left.f=10 \mu \mathrm{m} / \mathrm{rev}\right)$ 


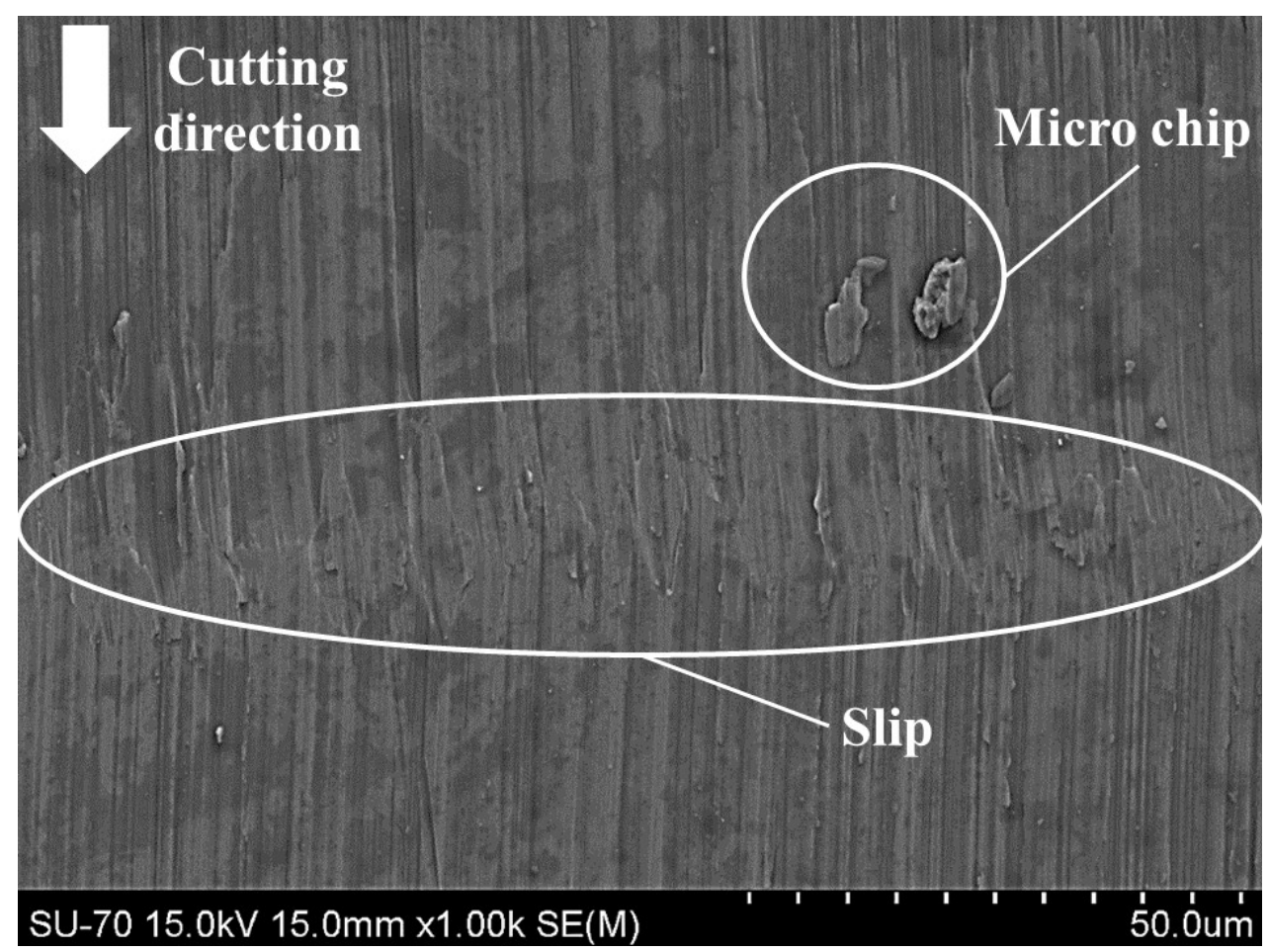

Figure 23 - SEM of the micro-machined surface for the cooling/lubricated micro-cutting

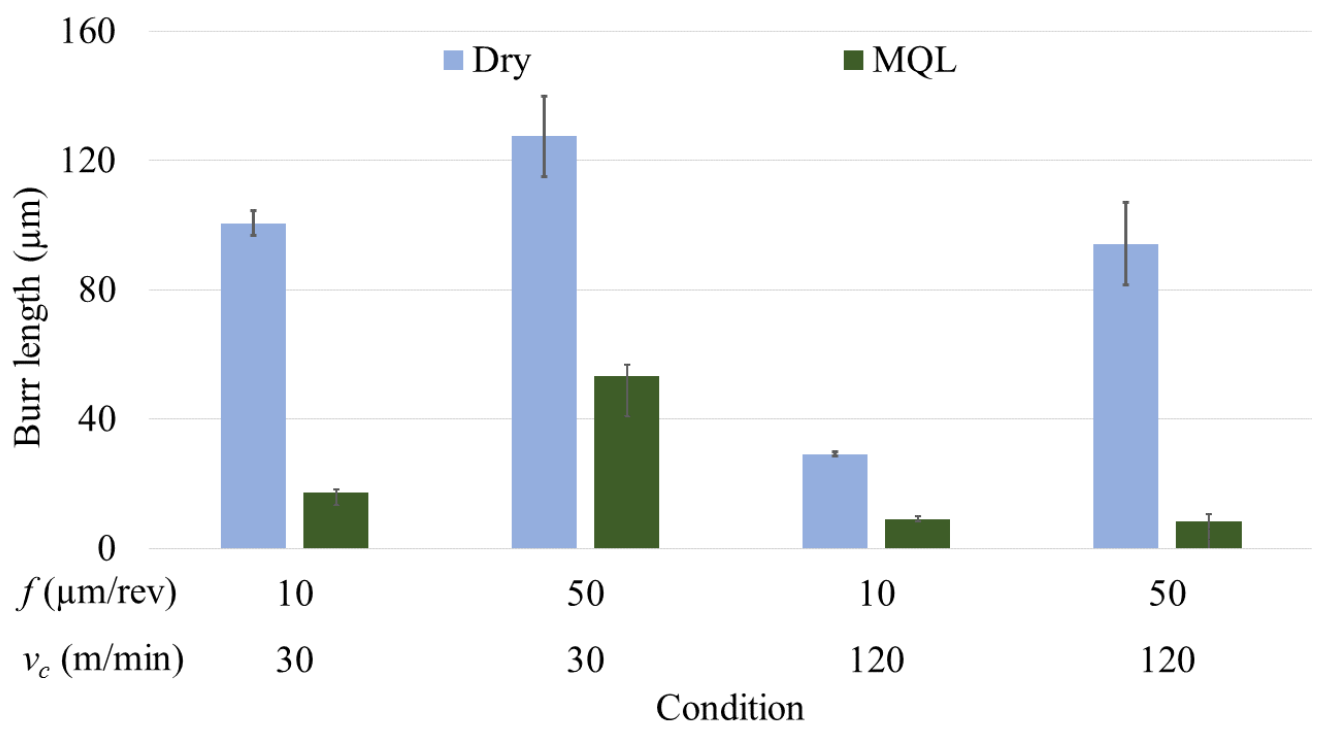

Figure 24 - Comparison of burr in the dry and cooling/lubricated micro-cutting 


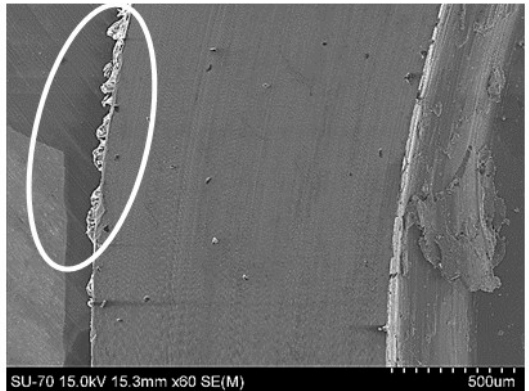

a) $v_{c}=120 \mathrm{~m} / \mathrm{min} ; f=10 \mathrm{~mm} / \mathrm{rev}$; dry

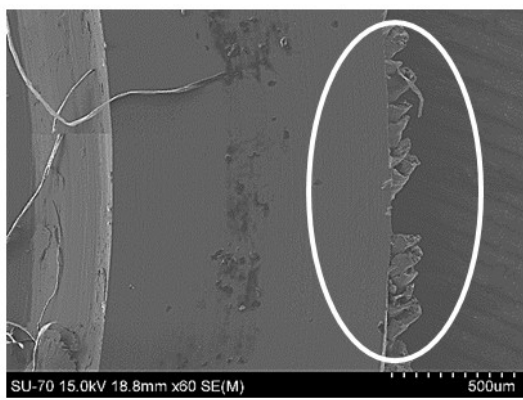

c) $v_{c}=120 \mathrm{~m} / \mathrm{min} ; f=50 \mathrm{~mm} / \mathrm{rev}$; dry

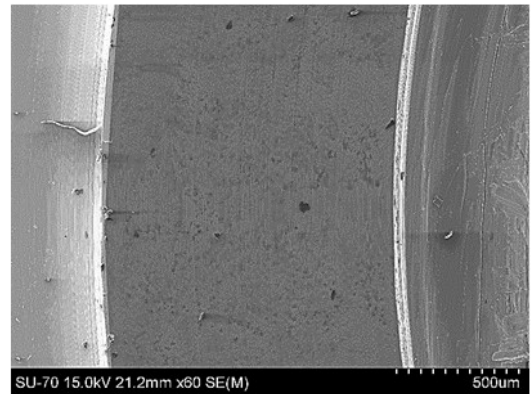

b) $v_{c}=120 \mathrm{~m} / \mathrm{min} ; f=10 \mathrm{~mm} / \mathrm{rev} ; \mathrm{MQL}$

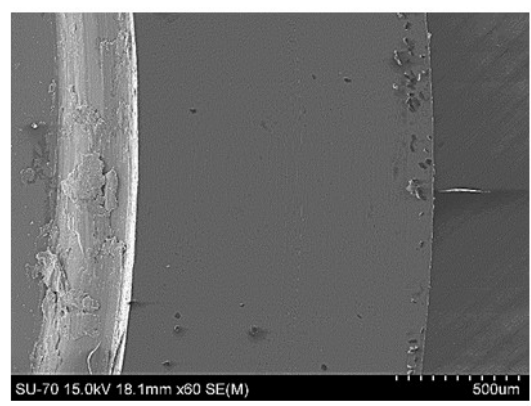

d) $v_{c}=120 \mathrm{~m} / \mathrm{min} ; f=50 \mathrm{~mm} / \mathrm{rev} ; \mathrm{MQL}$

Figure 25 - SEM to observe the burr formation in micro-cutting of the titanium alloy

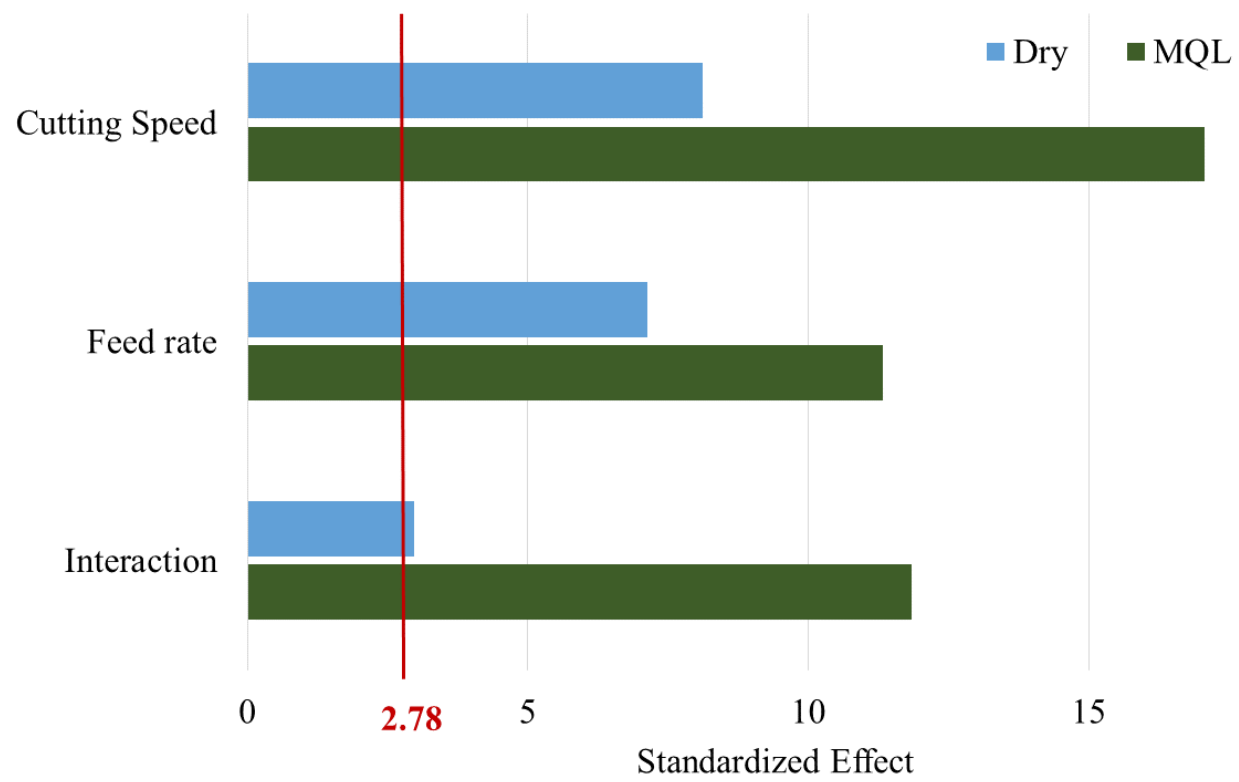

Figure 26 - Effect Pareto chart for the burr formation in the micro-cutting tests 


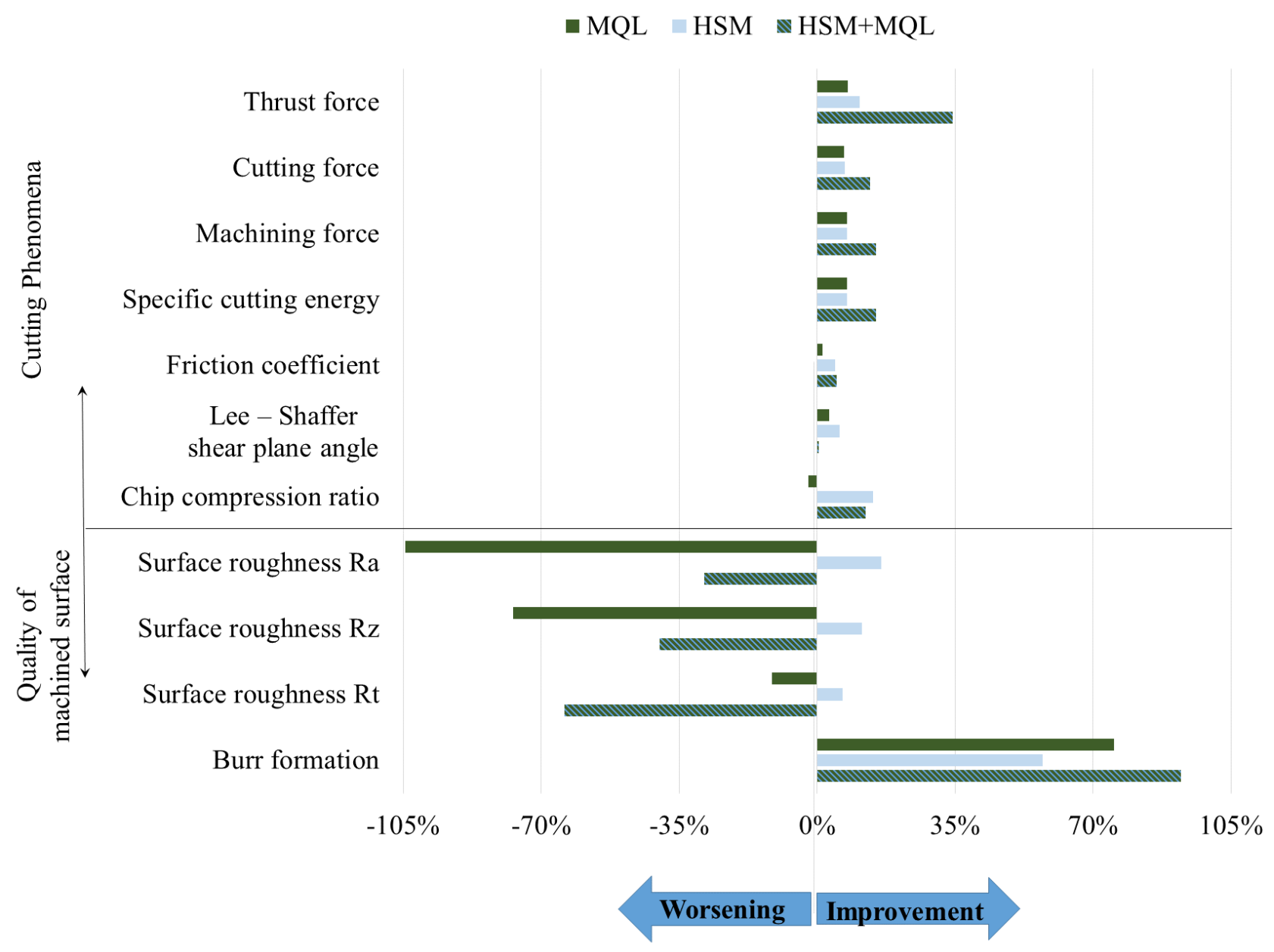

Figure 27 - Summary of the influence in the response of the micro-cutting tests 